\title{
Digital Reporting Formats: Users' Perceptions, Preferences and Performances
}

\author{
Erlane K Ghani. Universiti Teknologi Mara, Malaysia. erlanekg@ yahoo.com * \\ Fawzi Laswad. Massey University, New Zealand. \\ Stuart Tooley. Queensland University of Technology, Australia.
}

\begin{abstract}
This study examines users' perceptions of three digital reporting formats: PDF, HTML and XBRL. Using public accounting practitioners as participants, this study examines users' perceptions of different reporting formats used in disseminating financial information. This study includes examining the link between users' perceptions and preferred reporting format and whether these perceptions are similar to the quality of their decision in the completion of a specific task. This study follows Davis (1989, p. 320) who defined perceptions into 2: perceived usefulness as "the degree a user believes that a particular aid would enhance his performance" and perceived ease of use as "the degree to which a user believes that using a particular aid would reduce or be free of effort".

The results indicate that users' perceptions of usefulness among the digital reporting formats differ significantly. However, perceptions of ease of use are similar across the three digital reporting formats. Users' perceptions are also found to influence their preferred reporting format. The findings also show that users' perceptions of usefulness are analogous to their decision accuracy for HTML and XBRL formats but not for PDF format. Perceptions of ease of use, however, do not correspond to actual cognitive effort for all reporting formats. The results indicate
\end{abstract}

\footnotetext{
* Our thanks to Frank Hodge and Grant Boyd for their valuable insights. Our gratitude to the New Zealand Public accounting practitioners who participated in the study. Specifically, we would like to thank the anonymous reviewer and the participants of the APIRA Conference 2007 for their helpful comments on this paper. Lastly, we would like to thank the reviewers in IJDAR for their valuable comments.
} 
that if more advanced forms of digital reporting are to be encouraged, there is also the need for users to be made more aware of the benefits to be gained from the different forms of reporting.

Key words: Digital reporting formats; Decision quality; Perceptions; Preferences, Performances.

\section{INTRODUCTION}

The advancement of digital environment has seen the emergence of digital reporting literature. Digital reporting has been extensively researched in the past decade (Lymer and Tallberg, 1997; Ashbaugh et al., 1999; Lymer, 1999; Anderson, 2000; Oyelere et al., 2003; Smith, 2003; Fisher et al., 2004; Hodge and Pronk, 2006). This literature examines a range of issues including the factors that lead public and private organisations to adopt digital reporting (Ashbaugh et al., 1999; Craven and Marston, 1999; Deller et al., 1999; Anderson, 2000; Allam and Lymer, 2003; Oyelere et al., 2003; Laswad et al., 2005), and the extent of information provided digitally (Allam and Lymer, 2003; Smith, 2003; Fisher et al., 2004). Notably, these studies have mainly focused on preparers' perspectives.

More recently, a number of studies have focused on users' perspectives (Hodge, 2001; Beattie and Pratt, 2001; 2003; Dull et al., 2003; Hodge et al., 2002; 2004; Hodge and Pronk, 2006). These studies examine users' information needs, reporting format preferences and decision-making perspectives. The findings of these studies are analogous to those in the traditional reporting environment and other literatures: decision-makers demand a variety of information items, have different preferences for reporting formats and reporting formats have differing effects on decision-makers' performance.

The way in which information is presented (such as reporting format) is seen as a technology that can assist decision-makers to process large quantities of data and to perform the decision task more efficiently and effectively (Libby and Lewis, 1982; Rohrmann, 1986; Maines, 1995). This view is supported in previous studies that show reporting format has a direct impact on decision-makers' performance (Bricker and Nehmer, 1995; Hard and Vanecek, 1991; Ramarapu et al., 1997; Frownfelter-Lohrke, 1998; Hodge, 2001; Dull et al., 2003; Hodge et al., 2004). Few of these studies focused on decision quality and have used measures such as decision accuracy and cognitive effort as proxies for decision quality.

Most of the studies that linked reporting format and decision-makers, however, do not consider perception issues. One reason could be that researchers tend to place more focus on examining the effect of reporting format on decision-making, and ignore the concept that the success of a reporting format may rely on perception. Subjective measures such as perception, 
rather than objective measures, have been suggested as a determinant in technology usage (Beach and Mitchell, 1978), as often users need to have some knowledge of the technology before relying on it (Adams et al., 1992).

A body of the information system literature (such as Wright, 1975; Beach and Mitchell, 1978; Davis, 1989) proposes the existence of a relationship between decision makers' perceptions. Davis (1980) noted that the subjective measures of decision quality (usefulness and ease of use) are similar to the objective measures of decision accuracy and cognitive effort. However, and as noted by Davis (1989), this view has not been extensively researched and further research is required to examine whether these subjective measures are reflected in the quality of decision outcome.

This study takes up this challenge within the context of different technologies of digital reporting. It examines users' perceptions of the usefulness and ease of use of different reporting formats and the impact of reporting formats on the effectiveness (decision accuracy) and efficiency (cognitive effort) of the decision making process. Using an experiment setting, this study adapts the work of Hodge et al., (2004) and Davis (1989).

The remainder of this paper is structured as follows. The next section provides a review of relevant literature. Section 3 presents the research questions, research framework and hypotheses underpinning this study and section 4 outlines the research design. The results are presented in section 5. A discussion of the results and their implications are provided in the last section.

\section{LITERATURE REVIEW}

This study focuses on the reporting format of financial reports in a digital reporting environment. Several issues associated with reporting format have been identified in the accounting literature which include: decision accuracy (Hard and Vanecek, 1991; Bricker and Nehmer, 1995; Ramarapu et al., 1997; Frownfelter-Lohrke, 1998; Almer et al., 2003; Bizarro and Baldwin, 2004; Hodge et al., 2004); cognitive effort (Bricker and Nehmer, 1995; Tuttle and Kershaw, 1998; Dull et al., 2003); search behaviour (Watson and Driver, 1983; Purvis, 1989); affective responses (Kida et al., 1998; Rose, 2002); and persuasion, recall and satisfaction (Butler and Mautz, 1996; Clements and Wolfe, 1998; 2000). However, most of these studies do not consider perception issues from the users' perspective and therefore provide limited insight for preparers and system designers in understanding factors that ultimately influence users' acceptance of a technology (Adams et al., 1992). 
In the information system literature, several studies have used perceptions of ease of use and perceived usefulness of technology (e.g Panko, 1983; Davis, 1989; Straub and Wetherbe, 1989; Adams et al., 1992; Subramaniam, 1994). Davis (1989) examined perceived usefulness and perceived ease of use on users' intentions to use information technology in an attempt to develop and validate new measurement scales for the two variables, each of which were hypothesized to be determinants of computer usage. Davis $(1989$, p. 320) defined perceived usefulness as "the degree a user believes that a particular aid would enhance his performance". He defined perceived ease of use as "the degree to which a user believes that using a particular aid would reduce or be free of effort". Studies in this area conclude that perceived usefulness is a primary determinant and perceived ease of use is a secondary determinant of intention to use a technology (Adams et al., 1992; Subramaniam, 1994; Taylor and Brownfield, 2002).

Users may often share similar perceptions on the usefulness and ease of use of technologies that have a similar function (Adams et al., 1992). The suggestion that users would share similar perceptions of different technologies in a similar setting could be attributed to the fact that using either technology would provide similar functions and hence produce similar benefits (Adams et al., 1992). For example, Adams et al., (1992) examined the perceptions of users of two technologies (voice mail and electronic mail) and found that their participants viewed these two technologies as somewhat similar. However, as time changes, the effect of these technologies may vary (Adams et al., 1992) due to the evolvement of the technologies.

Within the accounting discipline, little is known about users' perceptions of different reporting formats. Beattie and Pratt (2003) provided some evidence that users of financial reports perceived the digital reporting formats as 'fairly useful'. However, similar study has yet to be conducted to provide further evidence on the perceptions of digital reporting formats. Such examination is important as it provides insights to preparers and systems designers who are trying to understand the factors that influence users' acceptance of a technology (Adams et al., 1992). It is likely that users would have similar perceptions on the usefulness and ease of use of digital reporting formats that have a similar function such as, for example, presenting financial information.

The link between users' perception of a format and preferred format has also been examined in the information systems literature (Beach and Mitchell, 1978; Davis, 1989; Adams et al., 1992). Davis (1989), Moore and Benbasat (1991) and Adams et al. (1992) found that users' perceptions often determine their preference for a technology. Although 
there has been research that examines preferences for reporting formats has been conducted in the digital reporting environment, the number of studies is sparse. Beattie and Pratt $(2001,2003)$ and Hodge and Pronk (2006) attempted to link users' preferences to reporting formats.

Beattie and Pratt $(2001 ; 2003)$ provided some evidence that users of financial reports perceived formats in the digital reporting environment as 'fairly useful' and found that users' preferences for a specific reporting format differ. They examined users' preferences for five types of reporting format: PDF, HTML, XBRL, spread-sheet and word-processed. They found distinct differences between the preferred formats for different groups; professional users preferred a spreadsheet format whereas novice users preferred HTML closely followed by a word-processed and a spreadsheet format. Beattie and Pratt's $(2001,2003)$ findings could be attributed to the various features and purpose of the technologies (Taylor and Brownfield, 2002), and that systems designers rely on feedback from real and potential users for the purpose of developing and improving their products (Davis, 1989). However, Beattie and Pratt's (2001, 2003) findings are limited to examining one feature, namely, portability of information.

Hodge and Pronk (2006) attempted to link users' preference to digital reporting format by examining whether novice and professional investors prefer the same reporting format in accessing their online quarterly financial statement. The study's methodology involved providing participants with two reporting formats, PDF and HTML, and requesting participants to search for information which was supposedly relevant to their investment decision task. They found professional users preferred PDF while novice users preferred HTML.

The findings of Beattie and Pratt $(2001 ; 2003)$ and Hodge and Pronk (2006) are consistent with studies that show users have different preferences among competing technologies (Rice and Steinfield, 1991; Adams et al., 1992; Hodge et al., 2004). However, these studies did not examine whether the participants' preferred reporting formats are influenced by their perceptions of the reporting formats.

Another body of literature indicates that users' perceptions of the usefulness and ease of use of a technology are not necessarily similar to the technology's actual usefulness (decision accuracy) and ease of use (cognitive effort) once a particular task has been performed (Sproull and Kiesier, 1986; Davis, 1989; Kleinmuntz and Schkade, 1993). Of consequence, limited knowledge and appreciation of the capabilities of a technology may have the undesired effect of deterring engagement with a technology that actually 
improves performance. However, there is a dearth of studies attempting to link perception of a reporting format to their actual performance outcome upon using that reporting format. The exclusion of an examination of users' perception and their link to actual performance provides a gap in knowledge. This argument is consistent with Davis (1989, p. 321) who states:

"This view has not been extensively researched whereby cost benefit research has primarily used objective measures of accuracy and effort in research studies, downplaying the distinction between objective and subjective accuracy and cognitive effort".

The psychology literature provides few insights on the link between perception of a technology and actual performance arising from the use of the technology. The literature suggests that subjective measures (perception) often are in disagreement with their objective counterparts (actual performance) (Wright 1975; Adelbratt and Montgomery, 1980). For example, Adelbratt and Montomery's (1980) results show that their participants gave higher ratings of compensatory rules compared to non-compensatory rules, despite the fact that the participants' perceptions were contrary to their actual performance. The results provide some indication that the participants may have perceived the technology as useful but, somehow, when they actually undertook the exercise, the results proved otherwise. Factors such as limited knowledge of the technology may contribute to these results. In this circumstance, users' perceptions were based on limited knowledge, and could eventually deter them from relying on a technology that would actually improve their decision-making outcomes.

In summary, within the digital reporting literature, there is a dearth of prior studies that examine users' perceptions of different reporting formats used in disseminating financial information and whether or not perceptions of usefulness and ease of use influence their preference of a reporting format as well as materialise in the completion of a specific task. Exploring this area would enhance the understanding of users' perceptions of reporting formats. This gap in knowledge provides the motivation and opportunity for the study reported in this paper. 


\section{RESEARCH QUESTIONS, FRAMEWORK AND HYPOTHESES}

\section{Research Questions}

According to Bertin (1983), the most appropriate format for a particular question is the one that improve decision-makers' performance. Different forms of presenting information make some aspects of the information displayed more apparent, and questions of different levels of complexity pertain to different characteristics or relationships within the information. An appropriate format would enable decision makers to process information more accurately and with less cognitive effort (Mackay et al., 1992; Hodge et al., 2004). Therefore, in sum, one format cannot be said as a technology to generally solve an issue; rather certain formats that can be used to achieve high performance in a specific task, may not be effective in a different task.

Several studies have examined the link between reporting formats and decision performance (Stock and Watson, 1984; Dickson et al., 1986; Iselin, 1988; Vessey, 1991; Mackay and Villareal, 1987; Hard and Vanecek, 1991; Stone and Schkade, 1991; Anderson and Kaplan, 1992; Ramarapu et al., 1997; Frownfelter-Lohrke, 1998; Dull et al., 2003). However, the scope of these studies is limited to examining the effect of reporting format on objective measures. Further, no studies within an accounting context have investigated the link between reporting formats and, what might be referred to as subjective measures of decision making performance (i.e. perceived usefulness and ease of use in performing decision task).

The advancement of the digital environment has led to the development of various digital reporting formats. Three reporting formats ${ }^{1}$ that are use in the dissemination of financial information and have wider availability are Portable Document Format (PDF) ${ }^{2}$, Hypertext Markup Language (HTML) $)^{3}$ and Extensible Business Reporting Language

\footnotetext{
${ }^{1}$ In the context of this study, the digital reporting formats are formats used to present financial information to users. The reporting of the financial information in using the 3 formats as viewed by the users is depending on the mediating software used to access the reporting formats.

${ }^{2}$ Portable Document Format (PDF) is a format used to preserve all formatting in a document, regardless of the platform used to read it. PDF is identical to print-based forms and easily accessible (Dull et al., 2003).

${ }^{3}$ Hypertext Mark-up Language (HTML) is a format used to describe the general structure of various kinds of documents (Wu and Vasarhelyi, 2004).
} 
$(\mathrm{XBRL})^{4}$. Such availability has provides opportunity for researchers to research on the subjective measures of decision making performance. Therefore, this study aims to examine the following research questions:

RQ1: How do users' perceived usefulness of each digital reporting format?

RQ2: How do users' perceived ease of use of each digital reporting format?

\section{Research Framework}

Figure 1 illustrates the framework that underpins this study. This framework is based on Libby and Lewis's $(1977 ; 1982)$ classification of variables affecting the ability of individuals to improve their task performance. The framework indicates that users' perception of reporting format also determines their preference of format. The framework also posits that a reporting format may impact on users' perception and actual performance and, further, users' perceptions of a particular reporting format may be similar to their actual performance using such a format.

Studies in the information systems literature show that users' perceptions of the usefulness and ease of use of a particular technology (such as reporting format) are not necessarily similar to the decision-making outcomes (Davis, 1989; Adams et al., 1992; Subramaniam, 1994; Taylor and Brownfield, 2002). The availability of digital reporting has given rise to the development of various reporting formats, providing opportunities for researching the link between users' perception and digital reporting formats. Therefore, this study examines users' perception and their actual performance in the decision-making process, using different reporting formats (PDF, HTML and XBRL). Hence, digital reporting format is the independent variable.

The digital reporting literature has recently expanded its scope to include reporting format (Beattie and Pratt, 2001; 2003; Hodge, 2001; Hodge et al., 2002; 2004; Hodge and Pronk, 2006). Apart from Beattie and Pratt's (2001; 2003) study, no further study on users' perceptions of the digital reporting formats is available. Studies in the information systems literature suggest that users often share similar perceptions (perceived usefulness and perceived ease of use) of technologies having similar functions (Panko, 1983; Paznik, 1987; Straub and Wetherbe, 1989; Adams et al., 1992). Arguably, such findings might

\footnotetext{
${ }^{4}$ The mark-up language in XBRL is used to format and structure the data in a document and provides an explanation of the meaning of the data (Wu and Vasarhelyi, 2004).
} 
also apply to digital reporting formats. Therefore, users' perception is a dependent variable in this study.

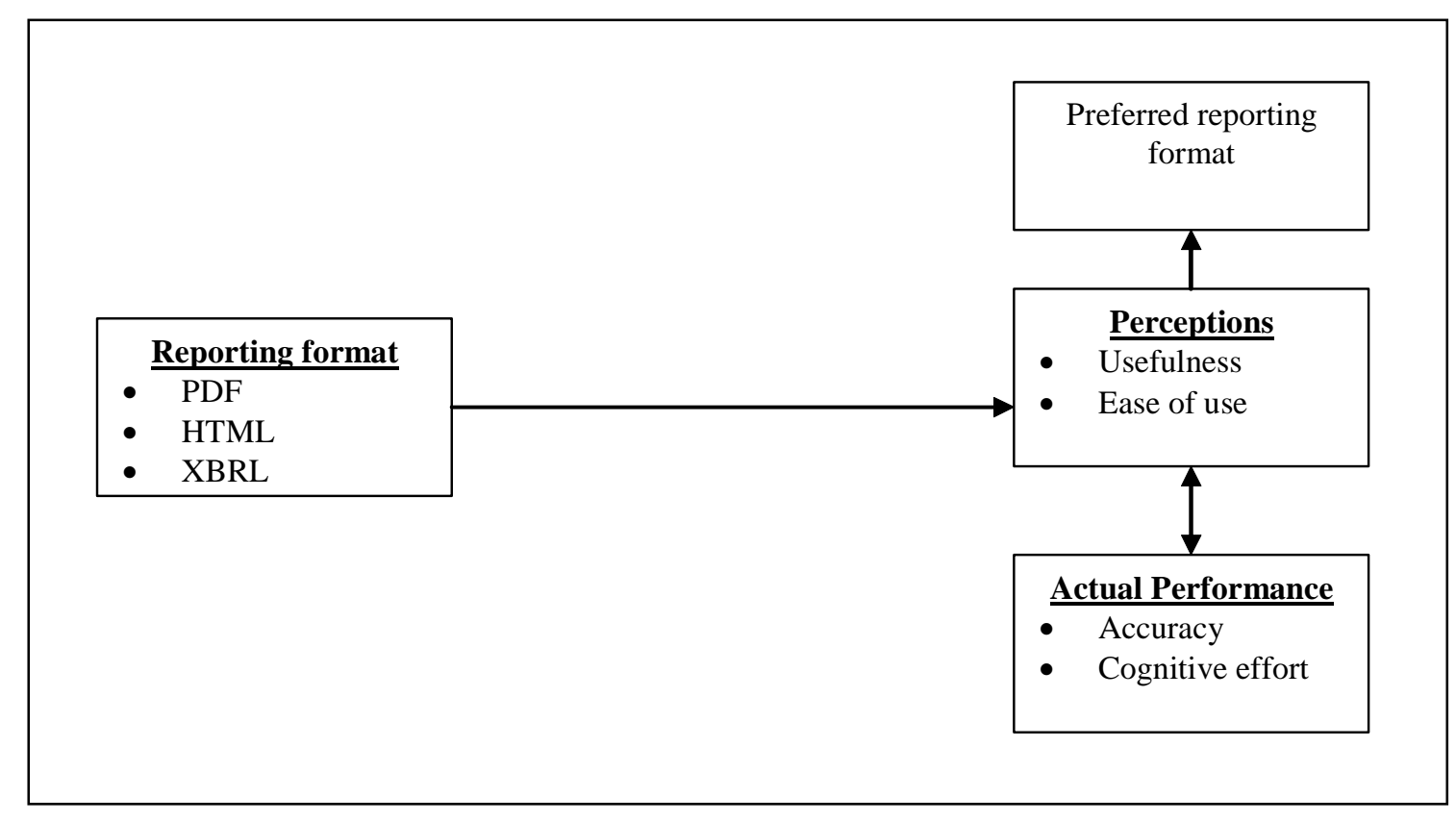

Figure 1. Research Framework

Studies have also suggested users' perceptions of the usefulness and ease of use of reporting format determines their preference of format (Beach and Mitchell, 1978; Davis, 1989; Kleinmuntz and Schkade, 1993). Although the existing studies in the digital reporting literature have examined users' perceptions and preference of reporting formats, these studies did not examine if there was consistency in users' initial perceptions and preferences, i.e, their selection of a particular reporting format after having gone through a research experiment exercise. Accordingly, users' preference is the second dependent variable.

Studies in the psychology and information system suggest that users' perceived usefulness and perceived ease of use of different technologies are often at odds with their actual level of decision accuracy and cognitive effort (Wright, 1975; Adelbratt and Montgomery, 1980; Davis, 1989). To date, this issue has not been examined in the reporting format and digital reporting literatures. Therefore, user's actual performance (decision accuracy and cognitive effort) is the third dependent variable. 


\section{Hypothesis}

Decision quality as measured by decision accuracy and cognitive effort are often used as measures in assessing the efficiency and effectiveness of a format in the decision making process (Kleinmuntz and Schkade, 1993). An appropriate format would enable decision makers to process information more accurately and with less cognitive effort (Mackay et al., 1992; Hodge et al., 2004). Although there are studies within the accounting context that have examined the link between decision quality and reporting format (such as Anderson and Kaplan, 1992; Ramarapu et al., 1997; Frownfelter-Lohrke, 1998; Dull et al., 2003), studies examining subjective measures are sparse.

Studies in information systems have found no significant difference between users' perceptions of technologies (Panko, 1983; Paznik, 1987; Straub and Wetherbe, 1989; Adam et al., 1992). Little is known, however, whether similar results would appear between the digital reporting formats. Investigating users' perceptions will provide an insight into the acceptance or rejection of a technology and provide an understanding of the factors that influence the success of digital reporting formats. This study examines users' perceptions of three digital reporting formats; PDF, HTML and XBRL. The null hypotheses are developed as follows:

- H1: There are no significant differences in users' perceived usefulness between the digital reporting formats.

- H2: There are no significant differences in users' perceived ease of use between the digital reporting formats.

Preference of reporting format was found to be dependent on the subjective measures of perceived usefulness and perceived ease of use (Davis, 1989; Kleinmuntz and Schkade, 1993). In the digital reporting environment, Beattie and Pratt (2001; 2003) found that participants had different preferences of reporting format. Similarly, Hodge and Pronk (2006) found that users preferred different reporting formats depending on whether they were novice users or expert users. However, these studies did not identify factors that might influence the participants' preference of reporting format.

Studies in psychology and information systems have suggested that users' perceived usefulness and ease of use of reporting format determines their preference of format (Beach and Mitchell, 1978; Davis, 1989; Kleinmuntz and Schkade, 1993). This link has not been thoroughly examined in the digital reporting literature and thus, it is difficult to 
generalise whether the results obtained in other bodies of literature would also applicable in digital reporting literature. Accordingly, this leads to the following hypotheses.

- H3: There is no association between users' perceived usefulness of a reporting format and their preference for the reporting format.

- H4: There is no association between users' perceived ease of use of a reporting format and their preference for the reporting format.

Studies in information systems suggest that users' initial perceptions of usefulness and ease of use of a reporting format may not necessarily be similar to actual accuracy of decision or cognitive effort (Wright, 1975; Adelbratt and Montgomery, 1980; Davis, 1989; Kleinmuntz and Schkade, 1993). However, this issue has not been examined in an accounting context. Since users' acceptance of a technology is highly dependent on their perceptions (Beach and Mitchell, 1978; Davis, 1989), users' perception may influence their decision to use a technology that may or may not improve their decision making outcome. The following hypotheses are developed:

- H5: There are no significant differences in users' perceived usefulness of a digital reporting format and the decision accuracy of decision outcome.

- H6: There are no significant differences in users' perceived ease of use of a digital reporting format and cognitive effort required for completion of a decision making task by using such a format.

\section{RESEARCH DESIGN}

This study focuses on users' perceptions of the usefulness and ease of use of different reporting formats in a digital reporting environment. Specifically, this study looks into whether:

1. Users' have different perceptions on the usefulness and ease of use of different reporting format.

2. Users' perceptions on the usefulness and ease of use of different reporting formats influence their preference of reporting format.

3. Users' perceptions of the usefulness and ease of use of different reporting formats correspond to decision making outcome (decision accuracy and cognitive effort). 
This study examines these issues by way of a research experiment and post experimental questionnaire.

\section{Participants}

Sixty two New Zealand public accounting practitioners volunteered to participate in this study. Public accountants are chosen as the research subjects as they perform a broad range of accounting, auditing, tax, and consulting activities for their clients (Vera-Munoz et al., 2001). One of their services is likely to assist and advise clients in investment decisions (Goldwater and Fogarty, 1995). Accounting practitioners also have a thorough knowledge and understanding of account preparation (Vera-Munoz et al., 2001).

The participants are public accounting practitioners who own public accounting firms and those who are working in public accounting firms. The public accounting practitioners selected must have experience in providing investment advice services to their clients. The participants are members of the New Zealand Institute of Chartered Accountants (NZICA). Only public accounting practitioners who are located in the major cities $^{5}$ of New Zealand were approached via formal letters as it was believed that there would be a higher number of public accounting practitioners who may have experience in investment decisions and therefore, a higher possibility of their participation in the study ${ }^{6}$.

\section{Experimental Design}

The research instrument consists of an experimental task and a post experimental questionnaire. The experiment task involves participants responding to an investment decision task. The experiment is adapted from the work of Hodge et al. (2004). Hodge et al. used two reporting formats, PDF (non-searchable) and XBRL (searchable). The searchable condition contained a search engine that allows participants to retrieve all information on the site related to a specific account. The non- searchable condition contained the same information (financial statements and footnotes) but in a static form.

The experiment material is based on fictitious financial statements of two firms; Firm A and Firm B. Each set of financial statements comprise a statement of financial

\footnotetext{
${ }^{5}$ The major cities are Auckland, Wellington and Christchurch.

${ }^{6}$ This study was conducted in between June to December 2006.
} 
performance (income statement), a statement of financial position (balance sheet), notes to the accounts, and a statement of cash flows ${ }^{7}$.

The financial statements for both firms are placed into three digital formats; PDF, HTML and XBRL. These reporting formats are chosen because of their availability to account preparers in the dissemination of financial performance and position. The conversion of the financial statements to XBRL is made using Microsoft Excel ${ }^{8}$. The translated financial statements are then uploaded to a webpage.

\section{Data Collection}

Out of the 62 participants, 23 participants had the opportunity to complete the research exercise in the researcher's presence. Hodge (2001) refers to these participants as 'in-lab' participants. Alternatively, 39 participants elected to access the research material on their own and at their own convenience. Hodge (2001) refers these participants as 'out-of-lab' participants. This latter option is given to participants in acknowledgement of their significant work commitments and thus they may not be able to attend 'in-lab' sessions.

To determine whether the participants in the in-lab group and the participants in the out-of-lab group attempt the research material in similar setting (for example, prolong breaks between experiment), the researcher informs the participants in the instruction page that the research material should be attempted in one sitting. Before testing the hypotheses of the study, the average amount of time taken to complete the experiment between the two groups are compared. This is important as it provides high assurance that these two groups attempt the experiment in similar setting.

The participants are also reminded in the instruction page to rely solely on the information included in the research material when making investment decision. Before testing the hypotheses of the study, the accuracy of extracting relevant values and the correct calculation of the four ratios requested in the research material between the two

\footnotetext{
${ }^{7}$ The financial statements and explanatory notes used in this study were chosen because the Securities and Exchange Commission (SEC) has suggested that financial statements should be used in an evaluation of the effectiveness of XBRL (SEC Release No. 33-8529, 2005).

${ }^{8}$ The SEC Chairman, Mr Christopher Cox has specifically identified the use of Excel to extract and process XBRL information (SEC, 2007). Further, this is similar to the model XBRL financial statement developed by XBRL-NZ (XBRLNZ 2004).
} 
groups are compared. This is important as it provides certain level of reliability that these two groups attempt the experiment in similar manner (for example, information usage).

Finally, the participants are allocated a reporting format. There are 21 participants in the PDF group, 20 participants in the HTML group and 21 participants in the XBRL group in this study. Each participant is advised to complete the research material based on the allocation reporting format. The purpose of such allocation is to ensure equal distributions of the reporting formats.

\section{Experiment Procedures}

The experiment is conducted in accordance with a series of sequential events. All participants are provided with two envelopes. The participants are required in the instruction page to complete the research material in sequential events starting from envelope 1 follows by envelope 2 . The participants commence the experiment by opening envelope one which contains a Compact Disk $(\mathrm{CD})^{9}$. Material on the CD includes an instruction page, a homepage containing general information about the nature of the business that the two firms are involved in, and the financial statements of the two firms. The participants begin their analysis by viewing each firm's homepage. In the firms' homepages, the participants click on the pre-selected reporting format allocated to them.

After reviewing the firm's financial information, the participants are asked to calculate four key ratios and to make an investment decision. The ratios are: return on assets; return on sales; return on fixed assets, and fixed assets turnover. The participants are then required to evaluate the financial performance and earnings potential of Firm A and Firm B and decide how much out of a total of $\$ 10,000$ they would invest in one or across both firms.

Once the experiment exercise is completed, the participants are asked to open envelope 2 which contains the post experimental questionnaire. The post experimental questionnaire consists of 3 sections. Section A is related to perceived usefulness. Section $\mathrm{B}$ is related to perceived ease of use and Section $\mathrm{C}$ contains questions on demographic profile.

\footnotetext{
${ }^{9} \mathrm{~A} C \mathrm{CD}$ was selected instead of the Internet for experimentation purposes as it provides a direct link to the webpage of the two firms with a low probability of "connection" problems occurring. The same amount of information applies to the digital reporting formats.
} 
Sections A and B of the questionnaire draw on the instrument used by Davis (1989) with appropriate modification to fit the purpose and context of this study. The participants are asked to view all three reporting formats before they start the post experimental questionnaire. The participants are required to complete a series of questions related to perceived usefulness and perceived ease of use for each of the reporting formats.

The participants are then asked to complete section $\mathrm{C}$ which consists of demographic information. Demographic information on each participant is requested including: age bracket, gender, and experience. Participants are also requested to provide a measure of their familiarity of each reporting format and their preference for a specific reporting format. The participants' preference provides the dependent measure for preference of reporting format.

\section{Dependent Measures}

Hypothesis 1 states that there are no significant differences in users' perceived usefulness between the digital reporting formats. Usefulness of reporting formats is assessed by way of a series of statements that require participants to indicate their views on each of the reporting formats. A 7-point scale is used, ranging from 1 (very strongly disagree) to 7 (very strongly agree). There are 9 statements related to perceived usefulness: usefulness of reporting format to improve work performance, informed investment decisions, well-formatted, volume of information, reliability, relevant information, reliance, usefulness and overall usefulness performance. The total score of the 9 statements is calculated and averaged to obtain an overall score to represent the perceived usefulness of each reporting format, hence producing three overall scores (PDF, HTML and XBRL formats). These overall scores are compared and a new score is subsequently created to code the highest mean score representing the most useful among the three reporting formats. The new score becomes the dependent measure to test hypothesis 1 .

Hypothesis 2 states that there are no significant differences in users' perceived ease of use between the digital reporting formats. Users' perceived ease of use is determined by asking the participants to assess 7 statements related to ease of use of the reporting formats using a 7-point scale of 1 (very strongly disagree) to 7 (very strongly agree). The 7 statements related to perceived ease of use are ease of learning, flexibility, skilful and understandable, ease of finding information, training and overall ease of use of the reporting formats. The total score of the 7 statements is calculated and averaged to obtain 
an overall score to represent the perceived ease of use of each reporting format. The overall scores are compared and a new score is created to represent the format most ease of use of the three reporting formats. The overall score for perceived ease of use becomes the dependent measure to test hypothesis 2 .

To test hypothesis 3 which states that there is no association between users' perceived usefulness of digital reporting formats and their preference of reporting formats, the response of each participant on the perceived usefulness of the reporting formats is averaged to obtain an overall score of the reporting formats. The overall score for perceived usefulness of each reporting format is compared and a new score is created to represent the most useful of the three reporting formats. This new variable represents the overall perceived usefulness. This score is then correlated to determine whether there is any association between perceived usefulness and preferred reporting formats.

To test hypothesis 4 which states that there is no association between users' perceived ease of use of digital reporting formats and their preference of reporting formats, the participants are requested to perceive the ease of use of the reporting formats using a 7-point scale of 1 (very strongly disagree) to 7 (very strongly agree). The response of each participant on the perceived ease of use of the reporting formats is averaged to obtain an overall score of the reporting formats. The overall score for perceived ease of use of each reporting format is compared and a new score is created to represent the format most easy to use (highest mean score) of the three reporting formats. This new variable represents the overall perceived ease of use which is used to test hypothesis 4 . This score is then correlated to the participants' preferred reporting formats to determine whether there is any association between perceived ease of use and preferred reporting formats.

Hypothesis 5 states that there are no significant differences in users' perceived usefulness of a digital reporting format and the decision accuracy of decision outcome by using such format. The total score (responses) of the 9 statements related to perceived usefulness for each reporting formats which is calculated and averaged to obtain an overall score to represent the perceived usefulness of each reporting format in testing hypothesis 1 is used as the measure for perceived usefulness. The participants' actual performance is determined by their accuracy in extracting relevant values and the correct calculation of the four ratios for each firm (Firm A and Firm B) as required in the 
experiment ${ }^{10}$. The participants' answers are marked to determine a score (Bricker and Nehmer, 1995; Dunn and Grabski, 2000). For each ratio calculated correctly a participant earns one mark, and therefore, a measure of decision accuracy per participant ranges between 0 and 4 for each firm, resulting in a total of 8 marks. The measurement for decision accuracy is deflated from 8 marks to 7 marks to represent a new score for decision accuracy. The overall score for perceived usefulness was then compared with the new mean score for decision accuracy to test hypothesis 5 .

Hypothesis 6 states that there are no significant differences in users' perceived ease of use of a digital reporting format and cognitive effort required for completion of a decision making task by using such a format. The total score (responses) of the 7 statements related to perceived ease of use for each reporting format which is calculated and averaged to obtain an overall score to represent the perceived ease of use of each reporting format in hypothesis 2 is used as the measure for perceived ease of use. The participants' actual performance for cognitive effort is determined by the total time taken to complete the experiment exercise ${ }^{11}$. In order to make an effective comparison of the actual time taken (which measures cognitive effort) to the perceived ease of use (which is measured using a 7-point scale), the actual time is converted into a 7-point scale. The higher the mean, the less the cognitive effort participants took to complete the experiment. This variable represents the dependent variable, cognitive effort. The overall score of perceived ease of use is then compared with the score of cognitive effort to test hypothesis 6 .

\section{RESULTS}

\section{Demographic statistics of participants}

Table 1 sets out the demographic attributes of participants. Twenty two percent of the participants have more than 20 years of accounting experience with half of the

\footnotetext{
${ }^{10}$ Decision accuracy refers to the ability of a strategy to produce an accurate outcome (Ashton, 1991). Decision accuracy is often measured by comparing the outcome with a benchmark (Frownfelter-Lohrke, 1998).

${ }^{11}$ Cognitive effort refers to total expenditure of cognitive resources to complete a task. It is often measured by total decision time or total number of cognitive operations. A group of studies have used time taken to measure cognitive effort (such as Hard and Vanecek, 1991; Bricker and Nehmer (1995); Ramarapu et al., 1997; Frownfelter-Lohrke, 1998; Dull et al., 2003).
} 
participants having more than 10 years of accounting experience including investment decision making.

Panel A: Level of Accounting Experience

\begin{tabular}{|l|l|l|}
\hline Experience & Number of subjects & $\%$ \\
\hline Less than 5 years & 15 & 24.2 \\
\hline 5 to 10 years & 15 & 24.2 \\
\hline 11 to 15 years & 12 & 19.4 \\
\hline $16-20$ years & 6 & 9.7 \\
\hline More than 20 years & $\underline{14}$ & $\underline{22.6}$ \\
\hline Total & 62 & 100.0 \\
\hline
\end{tabular}

Panel B: Familiarity with reporting formats

\begin{tabular}{|l|l|l|l|l|l|l|}
\hline \multirow{2}{*}{ Familiarity } & \multicolumn{9}{l|}{ REPORTING FORMAT } \\
\cline { 2 - 7 } & $\begin{array}{l}\text { PDF } \\
\text { subjects of }\end{array}$ & $\%$ & $\begin{array}{l}\text { Number of } \\
\text { subjects }\end{array}$ & $\%$ & $\begin{array}{l}\text { Number of } \\
\text { subjects }\end{array}$ & $\%$ \\
\hline $\begin{array}{l}\text { Extremely } \\
\text { familiar }\end{array}$ & 24 & 38.7 & 9 & 14.5 & 2 & 3.2 \\
\hline Very familiar & 18 & 29.0 & 12 & 19.4 & 2 & 3.2 \\
\hline Familiar & 20 & 16.1 & 11 & 17.7 & 1 & 1.6 \\
\hline Neither & 3 & 4.8 & 10 & 16.1 & 2 & 3.1 \\
\hline Unfamiliar & 2 & 1.6 & 7 & 11.3 & 5 & 8.1 \\
\hline $\begin{array}{l}\text { Very } \\
\text { unfamiliar }\end{array}$ & 0 & 0 & 3 & 4.8 & 12 & 19.4 \\
\hline $\begin{array}{l}\text { Extremely } \\
\text { unfamiliar }\end{array}$ & 6 & 9.7 & 10 & 16.1 & 38 & 61.3 \\
\hline Total & 62 & 100.00 & 62 & 100.0 & 62 & 100.0 \\
\hline
\end{tabular}

Panel C: Preferred reporting formats

\begin{tabular}{|c|c|c|c|}
\hline Reporting format & Frequency & $\%$ & Valid Percent \\
\hline PDF & 21 & 33.9 & 33.9 \\
\hline HTML & 22 & 35.5 & 35.5 \\
\hline XBRL & 19 & 30.6 & 30.6 \\
\hline Total & 62 & 100.0 & 100 \\
\hline
\end{tabular}


Panel D: Preferred reporting format for participants in different platforns

\begin{tabular}{|c|c|c|c|c|c|c|c|}
\hline \multirow{3}{*}{$\begin{array}{l}\text { Reporting } \\
\text { format }\end{array}$} & \multicolumn{6}{|c|}{ Preferred reporting format } & \multirow[b]{3}{*}{ Total } \\
\hline & \multicolumn{2}{|c|}{$P D F$} & \multicolumn{2}{|c|}{$H T M L$} & \multicolumn{2}{|c|}{$X B R L$} & \\
\hline & Frequency & $\%$ & Frequency & $\%$ & Frequency & $\%$ & \\
\hline PDF & 9 & 42.9 & 7 & 31.8 & 5 & 26.4 & 21 \\
\hline HTML & 4 & 19.0 & 9 & 40.9 & 7 & 36.8 & 20 \\
\hline XBRL & 8 & 38.1 & 6 & 27.2 & 7 & 36.8 & 21 \\
\hline Total & 21 & 100.0 & 22 & 100.0 & 19 & 100.0 & $\underline{62}$ \\
\hline
\end{tabular}

Table 1. Participants' demographic attributes, familiarity and preferences

A significant proportion of the participants are familiar with PDF (83\%) compared with 51\% and $8 \%$ of participants are familiar with HTML and XBRL, respectively. This is not surprising as PDF has been used over a longer period of time than HTML and XBRL as a reporting format (Baldwin et al., 2006). Preparers of corporate reports seem to prefer uploading their corporate reports using PDF since the appearance of the document is similar to the traditional hard-copy reporting model (Dull et al., 2003). The small number of participants who are familiar with XBRL may be attributable to its more recent emergence as a digital reporting technology (Baldwin et al., 2006) ${ }^{12}$.

When asked to state their preferred reporting format if they were to repeat the investment decision making task and could select any one of the three reporting formats $35 \%$ of the participants chose HTML, 33\% PDF and 30\% XBRL. Panel D shows that most of the participants who were exposed to one format in the initial phase of the experiment preferred to use it again in over any other format (PDF, 42.9\% and HTML, $40.9 \%$ ), except for the XBRL format, in which case participants reported a preference to use the PDF format instead. Reasons provided for preference for a particular format are summarised in Table 2.

\footnotetext{
12 The participants who are familiar with XBRL had some exposure with XBRL either from becoming members of XBRLNZ, conferences or had involved with the pilot study performed by XBRL-NZ. The pilot study involved 12 listed companies and was completed in 2005.
} 


\begin{tabular}{|c|c|c|}
\hline$P D F$ & HTML & $X B R L$ \\
\hline $\begin{array}{l}\text { Format which participants } \\
\text { were most familiar with. } \\
\text { Resistant to change. } \\
\text { Ability to read the whole } \\
\text { content of corporate reports } \\
\text { rather than relying solely on } \\
\text { the numbers. } \\
\text { Easier to obtain software to } \\
\text { download a PDF document } \\
\text { and most users would have } \\
\text { the software to download it. } \\
\text { No technical competencies } \\
\text { required for manipulating } \\
\text { data online. } \\
\text { Easier to use, clear, concise, } \\
\text { understandable and reliable. }\end{array}$ & $\begin{array}{l}\text { Easier to navigate and more } \\
\text { user friendly for viewing the } \\
\text { information. } \\
\text { The participants prefer the } \\
\text { way it links to the basis of } \\
\text { the information. } \\
\text { - Increases the under- } \\
\text { standability of information, } \\
\text { although may need to enter } \\
\text { the data into Excel } \\
\text { spreadsheet. } \\
\text { Easier to drill down into } \\
\text { numbers. }\end{array}$ & $\begin{array}{l}\text { The ability to be used as an } \\
\text { analytical tool. } \\
\text { Increases understandability } \\
\text { since the information required } \\
\text { could be viewed at the time it is } \\
\text { required. For example, an } \\
\text { information item in the financial } \\
\text { statement and footnotes could } \\
\text { be viewed simultaneously. } \\
\text { - It allows greater manipulation } \\
\text { of data into various categories. } \\
\text { - Helps to update figures } \\
\text { automatically without the need } \\
\text { to do extensive manipulations. } \\
\text { - It has the ability to standardise } \\
\text { results. } \\
\text { - Reduces effort. }\end{array}$ \\
\hline
\end{tabular}

Table 2. Participants' reasons for preferring a particular format

The participants in this study completed the experiment in in-lab and out-of-lab settings. To ensure that the participants in the in-lab group and the participants in the outof-lab group had attempt the research material in similar setting (for example, no prolong breaks between experiment), the researcher informs the participants in the instruction page that the research material should be attempted in one sitting.

Table 3 provides a comparison between the two groups in relation to the amount of time to complete the experiment. Panel A in table 2 shows 23 participants attempted the research instrument in the researcher's presence (in-lab) while 39 participants chose to attempt the research instrument at their convenience (out-of-lab). If the out-of-lab participants did not complete the experiment in one sitting, then the average time taken by them would be significantly longer than the in-lab participants.

The average amount of time taken to complete the experiment was compared. On average, the in-lab participants took about 13 minutes while the out-of-lab took 15 minutes to complete the experiment. T-test shows no significant differences $(0.159)$ with equal variances based on Levene's test (0.092) between these two groups. This indicates that in-lab and out-of-lab participants attempted the experiment in a similar timeframe. This is important as it provides high assurance that these two groups attempted the experiment similar setting. 
Panel A: Descriptive statistics of time to complete the experiment

\begin{tabular}{|l|l|r|l|l|}
\hline \multirow{2}{*}{ Completion time } & \multirow{2}{*}{ Number of subjects } & \multicolumn{3}{|c|}{ Time to complete the experiment } \\
\cline { 3 - 5 } & & Mean & Std deviation & Std error mean \\
\hline In-lab & 23 & 13.6087 & 6.72674 & 1.40262 \\
\hline Out-lab & 39 & 15.8974 & 5.71607 & 0.91530 \\
\hline
\end{tabular}

Panel B: Levene's test of equality of variance

\begin{tabular}{|l|l|c|}
\hline Dependent variable: Time to complete the experiment & \multicolumn{1}{|c|}{$F$} & Sig. \\
\hline Equal variances assumed & 3.829 & 0.092 \\
\hline
\end{tabular}

Panel C: T-test for in-lab and out-of lab experiment

\begin{tabular}{|l|c|c|c|c|c|c|c|}
\hline & & & & & & \multicolumn{2}{|c|}{$\begin{array}{c}\text { 95\% confidence interval of } \\
\text { the difference }\end{array}$} \\
\cline { 5 - 8 } & $T$ & $D f$ & Sig. & $\begin{array}{c}\text { Mean } \\
\text { difference }\end{array}$ & $\begin{array}{c}\text { Std. error } \\
\text { difference }\end{array}$ & Lower & Upper \\
\cline { 5 - 8 } $\begin{array}{l}\text { Equal } \\
\text { variances } \\
\text { assumed }\end{array}$ & -1.426 & 60 & 0.159 & -2.28874 & 1.60533 & -5.49987 & 0.92239 \\
\hline
\end{tabular}

Table 3. The experiment setting and time to complete the experiment

The participants in this study completed the experiment using the information presented in the research instrument. However, because the participants were allowed to complete the experiment in out-of-lab setting, there is a possibility that the participants could have accessed information outside of the research instrument ${ }^{13}$. If the participants solely relied on the information in the research instrument in completing the experiment exercise, then the accuracy in extracting and calculating ratios between the in-lab and outof-lab participants would not be significantly different. Table 4 provides a comparison between the two groups in relation to the accuracy in extracting and calculation of ratios.

The mean accuracy of extracting and calculating the ratios of the two groups was compared. On average, the in-lab participants scored about 4.3 while the out-of-lab participants scored about 5 . T-test shows no significant differences $(0.288)$ between these

\footnotetext{
${ }^{13}$ The participants were advised in the information sheet that to rely solely on the experiment instrument when completing the experiment exercise.
} 
two groups. This indicates that in-lab and out-of-lab participants attempted the experiment in a similar. This is important as it provides high assurance that these two groups attempted the experiment in similar setting (extracting and calculating the ratios by relying on the same information).

Panel A: Descriptive statistics of extracting and calculating ratios

\begin{tabular}{|l|l|l|l|c|}
\hline \multirow{2}{*}{ Completion time } & \multirow{2}{*}{ Number of subjects } & \multicolumn{3}{|c|}{ Extracting and calculating ratios } \\
\cline { 3 - 5 } & & Mean & Std deviation & Std error mean \\
\hline In-lab & 23 & 4.3043 & 2.85139 & 0.59456 \\
\hline Out-lab & 39 & 5.0769 & 2.67920 & 0.42902 \\
\hline
\end{tabular}

Panel B: Levene's test of equality of variance

\begin{tabular}{|l|c|c|}
\hline Dependent variable: Extracting and calculating ratios & $F$ & Sig. \\
\hline Equal variances assumed & 0.091 & 0.764 \\
\hline
\end{tabular}

Panel C: T-test for in-lab and out-of lab experiment

\begin{tabular}{|c|c|c|c|c|c|c|c|}
\hline & \multirow{2}{*}{$T$} & \multirow{2}{*}{$D f$} & \multirow{2}{*}{ Sig. } & \multirow{2}{*}{$\begin{array}{c}\text { Mean } \\
\text { difference }\end{array}$} & \multirow{2}{*}{$\begin{array}{l}\text { Std. error } \\
\text { difference }\end{array}$} & \multicolumn{2}{|c|}{$\begin{array}{c}95 \% \text { confidence interval } \\
\text { of the difference }\end{array}$} \\
\hline & & & & & & Lower & Upper \\
\hline $\begin{array}{l}\text { Equal } \\
\text { variances } \\
\text { assumed }\end{array}$ & -1.071 & 60 & 0.288 & -.77258 & 0.72131 & -2.21540 & 0.67025 \\
\hline
\end{tabular}

Table 4. Information usage

\section{Descriptive statistics of perceived usefulness}

This section presents the participants' responses on research question 1: How do users' perceived usefulness of each digital reporting format? Table 5 presents the descriptive statistics of perceived usefulness of PDF format. The results show that all the participants provide the highest mean score for statement number 2: "The reporting format would enable me to make a more informed investment decision" (4.4032), followed by statement number 5: "The reporting format contains too much irrelevant 
information for the investment decision task" (4.3710), and statement number 8: "I would find the reporting format useful in performing the investment decision task" (4.1935).

Table 5 also presents the descriptive statistics of perceived usefulness of HTML format. The results show that all the participants provide the highest mean score for statement number 3: "The reporting format is very useful for identifying information (well formatted)" (4.6774). The participants, in general, also agreed that HTML format enable them to make a more informed investment decision (statement number 2: mean score 4.3226).

\begin{tabular}{|l|l|c|c|c|}
\hline & Perceived usefulness $N=62$ & PDF & HTML & XBRL \\
\hline 1 & $\begin{array}{l}\text { The reporting format would enable me to accomplish } \\
\text { my investment decision task more quickly. }\end{array}$ & 4.1129 & 4.3548 & 4.8065 \\
\hline 2 & $\begin{array}{l}\text { The reporting format would enable me to make a more } \\
\text { informed investment decision. }\end{array}$ & 4.4032 & 4.3226 & 4.6290 \\
\hline 3 & $\begin{array}{l}\text { The reporting format is very useful for identifying } \\
\text { information (well formatted). }\end{array}$ & 4.2258 & 4.6774 & 4.4194 \\
\hline 4 & $\begin{array}{l}\text { The reporting format allows me to gather more } \\
\text { information for the investment decision task. }\end{array}$ & 4.0806 & 4.1774 & 5.0968 \\
\hline 5 & $\begin{array}{l}\text { The reporting format contains too much irrelevant } \\
\text { information for the investment decision task. }\end{array}$ & 3.6774 & 3.6129 & 4.0645 \\
\hline 6 & $\begin{array}{l}\text { The reporting format provides me with sufficient } \\
\text { information for the investment decision task. }\end{array}$ & 4.3710 & 4.3710 & 4.9516 \\
\hline 7 & $\begin{array}{l}\text { I do not have to rely on other reporting format upon } \\
\text { relying on this reporting to perform my investment } \\
\text { decision task. }\end{array}$ & 4.0806 & 4.4355 & 4.5968 \\
\hline 8 & $\begin{array}{l}\text { I would find the reporting format useful in performing } \\
\text { the investment decision task. }\end{array}$ & 4.1935 & 4.1452 & 5.0161 \\
\hline 9 & $\begin{array}{l}\text { Overall, I find the reporting format is useful for the } \\
\text { investment decision task. }\end{array}$ & 4.2581 & 4.4355 & 5.0645 \\
\hline
\end{tabular}

Table 5. Participants perceived usefulness of each reporting format ${ }^{14}$

Scale 1 (Very strongly disagree) to 7 (Very strongly agree)

\footnotetext{
${ }^{14}$ The Cronbach's Alpha test was used to determine the reliability of the variables of perceived usefulness. The test for all variables were examined for each reporting format and the reliability test results of all three formats are higher than 0.80 (lowest 0.838 to highest 0.937), which is somewhat similar to Davis (1989) and Adams et al. (1992).
} 
Table 5 also presents the descriptive statistics of perceived usefulness of XBRL format. The results show that all the participants provide the highest mean score for statement number 4: "The reporting format allows me to gather more information for the investment decision task" (5.0968), followed by statement number 8: "I would find the reporting format useful in performing the investment decision task" (5.0161), and statement number 6: "The reporting format provides me with sufficient information for the investment decision task" (4.9516).

In summary, the descriptive statistics of perceived usefulness show that in general, the participants who responded to the questionnaire agree that all three reporting formats are useful for investment decision task. The results show that overall, the participants perceived XBRL as the most useful compared to PDF and HTML formats.

\section{Descriptive statistics of perceived ease of use}

This section presents the participants' responses on research question 2: How do users' perceived ease of use of each digital reporting format? Table 6 presents the descriptive statistics of perceived ease of use of PDF format. The results show that all the participants provide the highest mean score for statement number 1: "I can easily learn how to use the reporting format" (5.1129), followed by statement number 3: "I can easily become skilful in using the reporting format" (5.0806). The participants, however, generally agree that the PDF format does not enable them to retrieve and manipulate the information for the investment decision task (statement number 5: mean score 3.6129).

Table 6 also presents the descriptive statistics of perceived ease of use of HTML format. The results show that all the participants, irrespective of which format they were pre-allocated in the experiment, provide the highest mean score for statement number 3 : "I can easily become skilful in using the reporting format" (5.2581). This indicates that the participants have the same perception on HTML format with regards to easily becoming skilful in using the reporting format.

Finally, table 6 presents the descriptive statistics of perceived ease of use of XBRL format. The results show that all the participants provide the highest mean score for statement number 6: "Further training will improve my performance in using the reporting format" (5.7742), followed by: "The reporting format enables them to easily retrieve and manipulate the information for the investment decision task" (5.4194), and: "I can easily become skilful in using the reporting format" (4.7419). 


\begin{tabular}{|l|l|l|l|l|}
\hline & Perceived usefulness $N=62$ & PDF & HTML & XBRL \\
\hline & \multicolumn{1}{|l|}{ Mean } & Mean & Mean \\
\hline 1 & I can easily learn how to use the reporting format. & 5.1129 & 5.1129 & 4.3065 \\
\hline 2 & The reporting format is very clear and understandable. & 5.0484 & 5.1290 & 4.2581 \\
\hline 3 & I can easily become skilful in using the reporting format. & 5.0806 & 5.2581 & 4.7419 \\
\hline 4 & $\begin{array}{l}\text { I can easily find the information that I require for my } \\
\text { investment decision task. }\end{array}$ & 4.3871 & 4.8226 & 4.8226 \\
\hline 5 & $\begin{array}{l}\text { The reporting format enables to easily retrieve and } \\
\text { manipulate the information for the investment decision } \\
\text { task. }\end{array}$ & 3.6129 & 3.7581 & 5.4194 \\
\hline 6 & $\begin{array}{l}\text { Further training will improve my performance in using } \\
\text { the reporting format. }\end{array}$ & 3.6452 & 4.0484 & 5.7742 \\
\hline 7 & Overall, I find the reporting format is very easy to use. & 4.9516 & 4.9194 & 4.6935 \\
\hline
\end{tabular}

Table 6. Participants'perceived ease of use of each reporting format ${ }^{15}$ Scale 1 (Very strongly disagree) to 7 (Very strongly agree)

In summary, the participants agree that in general, all three reporting formats as being easy to use when performing investment decision task. The results also show that overall ease of use is leaded by HTML format, followed by PDF and XBRL.

\section{Perception differences on usefulness}

This section presents the results of hypothesis 1 . Hypothesis 1 states that there are no significant differences in users' perceived usefulness between the digital reporting formats. Friedman test was used to determine whether the users have perceived the three reporting formats in terms of usefulness differently.

Panel A of Table 7 shows the descriptive statistics for perceived usefulness of reporting formats by the participants. The results show that the participants provide the highest mean score for XBRL format (4.7348), followed by HTML format (4.2632) and PDF format (4.1481).

Panel B, Table 7 shows the ranking of the reporting formats. The results show that the mean rank for XBRL is the highest (2.31), followed by HTML (1.98). The lowest mean rank is the PDF format (1.71). This indicates that the participants perceived XBRL

\footnotetext{
${ }^{15}$ The Cronbach's Alpha test was used to determine the reliability of the variables of perceived ease of use. The test for all variables were examined for each reporting format and the reliability test results of all three formats are higher than 0.80 (lowest 0.767 to highest 0.937), which is somewhat similar to Davis (1989) and Adams et al. (1992).
} 
format as most useful among the three reporting formats. The results also show significant difference of users' perceived usefulness of the three reporting formats (0.003). Therefore, the results reject hypothesis 1 that there are no significant differences in users' perceptions of the usefulness of reporting formats.

Panel A: Descriptive statistics of perceived usefulness

\begin{tabular}{|c|c|c|c|}
\hline Perceived usefulness & N & Mean & Standard deviation \\
\hline PDF & 62 & 4.1481 & 0.95981 \\
\hline HTML & 62 & 4.2632 & 1.07708 \\
\hline XBRL & 62 & 4.7348 & 1.42149 \\
\hline
\end{tabular}

Panel B: Friedman test of perceived usefulness

\begin{tabular}{|c|c|c|c|c|}
\hline Perceived usefulness & $\mathrm{N}$ & Rank & $\mathrm{X}^{\mathbf{2}}$ & Sig \\
\hline PDF & 62 & 1.71 & 11.930 & 0.003 \\
\hline HTML & 62 & 1.98 & & \\
\hline XBRL & 62 & 2.31 & & \\
\hline
\end{tabular}

Table 7. Users` perceptions of usefulness

\section{Perception differences on ease of use}

In this section the results from testing hypothesis 2 are presented. Hypothesis 2 states that there are no significant differences in users' perceptions of the ease of use of digital reporting formats. Friedman test was used to determine whether the users have perceived the reporting formats in terms of ease of use differently.

Panel A: Descriptive statistics of perceived ease of use

\begin{tabular}{|c|c|c|c|}
\hline Perceived ease of use & $\mathrm{N}$ & Mean & Standard deviation \\
\hline PDF & 62 & 4.5768 & 1.09568 \\
\hline HTML & 62 & 4.7050 & 1.12648 \\
\hline XBRL & 62 & 4.8452 & 1.24428 \\
\hline
\end{tabular}

Panel B: Friedman test of perceived ease of use

\begin{tabular}{|c|c|c|c|c|}
\hline Perceived ease of use & N & Rank & $\mathrm{X}^{\mathbf{2}}$ & Sig \\
\hline PDF & 62 & 1.85 & 2.398 & 0.301 \\
\hline HTML & 62 & 2.07 & & \\
\hline XBRL & 62 & 2.08 & & \\
\hline
\end{tabular}

Table 8. Users' perceptions of ease of use 
Panel A, Table 8 shows the descriptive statistics for perceived ease of use of the reporting formats by all participants. The results show that the participants provided the highest mean score for XBRL format (4.8452), followed by HTML format (4.7050) and PDF format (4.5768). The results indicate that XBRL format is the most easy to use of the three reporting formats.

Panel B, Table 8 shows the ranking of the reporting formats on the perceived ease of use. The results show that the mean rank for XBRL is the highest for XBRL (2.08), followed closely by HTML (2.07). PDF format was ranked the lowest (1.85). This finding supports the descriptive results in panel A, Table 8 that the participants perceived XBRL format as most useful among the three reporting formats. The results in panel B, Table 8, however, show no significant difference of users' perceived usefulness of the three reporting formats (0.301). Therefore, the results support hypothesis 2 that there are no significant differences in users' perceptions of ease of use of the reporting formats.

\section{Perceived usefulness and preference}

In this section the results from testing hypothesis 3 are presented. Hypothesis 3 states that there is no association between users' perceptions of the usefulness of digital reporting formats and their preference of reporting formats. A Chi-square correlation test was used to determine the association between perceived usefulness and preferred reporting formats.

Panel A, Table 9 provides the descriptive statistics (cross tabulation) for participants' perceived usefulness and their preference of reporting formats. In general, the results show participants who perceived that a reporting format is useful, tended to prefer that reporting format for performing their future investment decision task. As shown in Panel A, Table 9, participants perceiving PDF as most useful prefer to use PDF format (33\%) compared to HTML format (13\%) and XBRL format (10\%) in their investment decision tasks. On the other hand, participants perceiving HTML as most useful, tend to prefer HTML (45\%) in performing investment decision tasks.

Panel B, Table 9 presents the results showing the association between perceived usefulness and preferred reporting format using a Chi-square correlation test. The results show a significant correlation ( $\mathrm{r}=0.002)$ between participants' perceived usefulness and their preference of a reporting. The results indicate that participants' preference of a reporting format is influenced by their perceptions of the reporting format. This suggests 
that users' perception of the usefulness of a reporting format is an important determinant in their preference for a reporting format. Therefore hypothesis 3 is not supported.

Panel A: Cross tabulation of perceived usefulness and preference of reporting formats (all participants)

\begin{tabular}{|c|c|c|c|c|c|c|c|c|}
\hline \multirow{2}{*}{$\begin{array}{c}\text { Perceived } \\
\text { useful }\end{array}$} & \multicolumn{5}{|c|}{ Preferred reporting format } & \multicolumn{3}{c|}{ Total } \\
\cline { 2 - 9 } & \multicolumn{2}{|c|}{ PDF } & \multicolumn{2}{c|}{ HTML } & \multicolumn{2}{c|}{ XBRL } & \multicolumn{2}{c|}{ N } \\
\cline { 2 - 9 } & Number & $\%$ & Number & $\%$ & Number & $\%$ & Number & $\%$ \\
\hline PDF & 7 & 33.3 & 3 & 13.6 & 2 & 10.5 & 12 & 33.3 \\
\hline HTML & 4 & 19.0 & 10 & 45.5 & 0 & 0 & 14 & 22.6 \\
\hline XBRL & 10 & 47.7 & 9 & 40.9 & 17 & 89.5 & 36 & 58.1 \\
\hline & 21 & 100 & 22 & 100 & 19 & 100 & 62 & 100 \\
\hline
\end{tabular}

Panel B: Chi-square test: users' perceptions on usefulness and preferred reporting formats

\begin{tabular}{|c|c|c|c|}
\hline & Value & Df & Sig. (2-sided) \\
\hline Pearson Chi-Square & $17.499(\mathrm{a})$ & 4 & 0.002 \\
\hline Likelihood Ratio & 20.136 & 4 & 0.000 \\
\hline Linear-by-Linear Association & 6.439 & 1 & 0.011 \\
\hline Number of subjects & 62 & & \\
\hline
\end{tabular}

Table 9. Users' perception of usefulness and their preference of reporting format

\section{Perceived use of use and preference}

In this section the results from testing hypothesis 4 are reported. Hypothesis 4 states that there is no association between users' perceptions of the ease of use of digital reporting formats and their preference of reporting format. A Chi-square correlation test was used to determine the association between perceived ease of use and preferred reporting formats.

Panel A, Table 10 provides the descriptive statistics for participants' perceived ease of use and their preference of reporting formats. In general, the results show participants who perceived that a reporting format is easy to use, tended to prefer that reporting format for performing their future investment decision task. As shown in Panel A, Table 10 participants perceiving PDF format as the most easy to use prefer to use PDF format (52\%) in their investment decision tasks. On the other hand, participants perceiving HTML as the most easy to use, tend to prefer HTML format (36\%) in performing investment decision tasks. Similar results occur with XBRL format. 
Panel A: Cross tabulation of perceived ease of use and preference of reporting formats (all participants)

\begin{tabular}{|c|c|c|c|c|c|c|c|c|}
\hline \multirow{2}{*}{$\begin{array}{c}\text { Perception } \\
\text { ease of use }\end{array}$} & \multicolumn{6}{|c|}{ Preferred reporting format } & \multicolumn{3}{c|}{ Total } \\
\cline { 2 - 10 } & \multicolumn{2}{|c|}{ PDF } & \multicolumn{2}{c|}{ HTML } & \multicolumn{2}{c|}{ XBRL } & \multicolumn{2}{c|}{} \\
\cline { 2 - 9 } & Number & $\%$ & Number & $\%$ & Number & $\%$ & Number & $\%$ \\
\hline PDF & 11 & 52.4 & 5 & 22.7 & 2 & 10.5 & 18 & 29.0 \\
\hline HTML & 4 & 19.0 & 8 & 36.4 & 2 & 10.5 & 14 & 22.6 \\
\hline XBRL & 6 & 28.6 & 9 & 40.9 & 15 & 79.0 & 30 & 48.4 \\
\hline & 21 & 100 & 22 & 100 & 19 & 100 & 62 & 100 \\
\hline
\end{tabular}

Panel B: Chi-square test: Users' perceptions of ease of use and preferred reporting formats

\begin{tabular}{|c|c|c|c|}
\hline & Value & df & Sig. (2-sided) \\
\hline Pearson Chi-Square & $15.301(\mathrm{a})$ & 4 & 0.004 \\
\hline Likelihood Ratio & 15.029 & 4 & 0.005 \\
\hline Linear-by-Linear Association & 11.306 & 1 & 0.001 \\
\hline Number of subjects & 62 & & \\
\hline
\end{tabular}

Table 10. Users' perceptions of ease of use and their preference of reporting format

Panel B, Table 10 also presents the results that show the association between perceived ease of use and preferred reporting format. The results show a statistically significant correlation $(r=0.004)$ between participants' perceived ease of use of a reporting format and their preference for a particular format. The results indicate that the participants' preference of a reporting format is influenced by their perceptions of ease of use. Therefore, hypothesis 4 is not supported as there is evidence that users' perceived ease of use is an important criteria used to determine preference of reporting format.

\section{Perceived usefulness and decision accuracy}

In this section hypothesis 5 is tested. Hypothesis 5 states that there are no significant differences between users' perceived usefulness of a digital reporting format and decision accuracy by using such format. The Wilcoxon Signed Rank Test was used to test hypothesis 5 .

Panel A of Table 11 shows the descriptive statistics for participants' perceived usefulness and their actual performance (decision accuracy) in the experiment. The results show that the perceived usefulness of the reporting formats was higher than the decision accuracy by using such formats. The mean difference of perceived usefulness and the decision accuracy of the PDF group is the highest (0.8790), compared with that 
for the HTML group (0.1830) and the XBRL group (0.0588). This result indicates that participants in the PDF group had a higher perception of the usefulness of PDF format compared to how useful the format was when a task was performed. The results also indicate that among the three reporting formats, participants in the XBRL group has the least mean difference between the perception of usefulness and their actual performance (decision accuracy) when using such a format.

Panel A: Descriptive statistics for perceived and actual performance of usefulness in each group

\begin{tabular}{|c|c|c|c|c|}
\hline $\begin{array}{c}\text { Reporting format perceived/ used in } \\
\text { the experiment }\end{array}$ & Usefulness & $\mathrm{N}$ & Mean & Std. deviation \\
\hline PDF & Perceived & 21 & 4.1314 & 1.04732 \\
& Decision accuracy & 21 & 3.2524 & 2.10851 \\
\hline HTML & Perceived & 20 & 4.4720 & 1.06798 \\
& Decision accuracy & 20 & 4.2890 & 2.42260 \\
\hline XBRL & Perceived & 21 & 4.8100 & 1.45672 \\
& Decision accuracy & 21 & 4.7512 & 2.04318 \\
\hline
\end{tabular}

Panel B: Wilcoxon Signed Ranks test between perceived usefulness and decision accuracy in each group

\begin{tabular}{|c|c|c|c|c|}
\hline $\begin{array}{c}\text { Reporting format perceived/used in the } \\
\text { experiment }\end{array}$ & Mean change & Z & d.f & Sig. \\
\hline PDF & 0.8790 & -1.686 & 20 & 0.092 \\
\hline HTML & 0.1830 & -0.373 & 19 & 0.709 \\
\hline XBRL & 0.0588 & -0.052 & 20 & 0.958 \\
\hline
\end{tabular}

Table 11. Users' perceptions versus actual performance of usefulness

The results given in Panel A, Table 11 indicate a greater point of difference between perceived usefulness and decision accuracy for the PDF group and this difference is marginally significant difference $(\mathrm{p}=0.092)$, However, the results show no significant differences between all groups' perceived usefulness and decision accuracy for the reporting formats (HTML format, $\mathrm{p}=0.709$; and XBRL format, $\mathrm{p}=0.958$ ) as shown in Panel B, Table 11. Therefore, hypothesis 5 is supported for HTML and XBRL but not PDF.

\section{Perceived ease of use and cognitive effort}

In this section hypothesis 6 is tested. Hypothesis 6 states that there are no significant differences in users' perceived ease of use of a digital reporting format and cognitive 
effort required for completion of a decision making task by using such a format. The Wilcoxon Signed Rank Test was used to test hypothesis 6.

Panel A of Table 12 shows the descriptive statistics for participants' perceived ease of use and their actual performance (cognitive effort) in the experiment. The results show that in general, the perceived ease of use of the reporting formats was higher than the cognitive effort. The participants who were pre-allocated PDF format have the least mean difference between the perceived ease of use and cognitive effort (0.1461), compared with the mean difference of the participants who were pre-allocated the XBRL format (0.8034) and HTML format (1.000). The results indicate that participants in the XBRL groups perceived XBRL format to be highly ease of use. However, their actual performance (cognitive effort) upon using the format in completing the experiment task did not parallel to their high perception of ease of use.

Panel A: Descriptive statistics of perceived ease of use and cognitive effort

\begin{tabular}{|c|c|c|c|c|}
\hline $\begin{array}{c}\text { Reporting format perceived/ used } \\
\text { in the experiment }\end{array}$ & Ease of use & Mean & $\begin{array}{c}\text { Number of } \\
\text { subject }\end{array}$ & $\begin{array}{c}\text { Std. } \\
\text { deviation }\end{array}$ \\
\hline PDF & Perceived & 4.5271 & 21 & 1.29082 \\
Cognitive effort & 4.3810 & 21 & 1.43095 \\
\hline HTML & Perceived & 4.9500 & 20 & 0.34393 \\
& Cognitive effort & 3.9500 & 20 & 1.53811 \\
\hline XBRL & Perceived & 4.8986 & 21 & 1.22202 \\
& Cognitive effort & 4.0952 & 21 & 1.33809 \\
\hline
\end{tabular}

Panel B: Wilcoxon Signed Ranks T-test between perceived ease of use and cognitive effort in each group

\begin{tabular}{|c|c|c|c|c|}
\hline $\begin{array}{c}\text { Reporting format perceived/ used in the } \\
\text { experiment }\end{array}$ & Mean change & Z & d.f & Sig. \\
\hline PDF & 0.1461 & -0.365 & 20 & 0.715 \\
\hline HTML & 1.0000 & -2.020 & 19 & 0.043 \\
\hline XBRL & 0.8034 & -2.156 & 20 & 0.031 \\
\hline
\end{tabular}

Table 12. Users' perceptions of ease of use and cognitive effort

The results suggest that participants in the HTML and XBRL groups perceived their respective formats as highly reducing their cognitive effort, but their actual performance does not reflect their perceived ease of use. Therefore, hypothesis 6 is not supported for HTML and XBRL formats but is supported for PDF format. 


\section{DISCUSSION AND IMPLICATIONS}

In this study, users' perceptions of the usefulness and ease of use of different reporting formats in a digital reporting environment were examined. The findings were presented in three parts and the discussion presented below follows the same sequence.

In the first part of the results, an analysis of users' perceived usefulness and perceived ease of use across the reporting formats was reported. On average, most of the participants agreed that the reporting formats in the digital reporting environment are useful and are easy to use. The results of this study are also consistent with Beattie and Pratt (2003) where their respondents perceived all the digital reporting formats as "fairly useful". However, the results of this study show that the users' perceptions of usefulness among the reporting formats differ significantly. The results indicate that XBRL format would be a useful tool to rely on when it comes to performing investment decision task compared to PDF and HTML.

The results also show that the users perceived all reporting formats as easy to use. This was reflected in further analysis that showed no significant difference in the users' perceived ease of use of the reporting formats. The results found here support previous studies in the information systems literature which report users' perceptions of technologies which have similar purpose are homogenous (Panko, 1983; Paznik, 1987; Straub and Wetherbe, 1989).

The results showing that users' perceptions of ease of use are homogenous across the reporting formats derive from the limited knowledge about HTML and XBRL that cause the users to perceive the reporting format differently from its actual benefits. As noted by Davis (1989), the limited knowledge and appreciation of the capabilities of a technology may have the undesired effect of deterring engagement with a technology that actually improves performance (Davis, 1989). This finding also suggests that even when users are given the opportunity to perform a decision-making task using a new reporting format, they may still perceive another reporting format as better.

The results showing users' perceptions are similar across the different digital presentation formats could also indicate that users do not provide much weight on the adoption of new reporting format such as XBRL as they may perceive the benefits are not significantly difference compared to other reporting formats. Therefore, it is understandable as to why the level of adoption achieved by XBRL is disappointing when compared with the early predictions made for its success. 
However, the results show that there are significant differences in the perceived usefulness among the reporting formats. One possible reason is contributed by the fact that for a certain period of time, the effect of a few technologies (such as reporting formats) may be consistent (Davis, 1989). However, as time changes, the effect of these technologies may vary (Adams et al., 1992) due to the evolvement of the technologies. Therefore, users' perceptions may also vary across time depending on the change in the nature of the reporting formats. This argument is consistent in the earlier results of perceived usefulness. It is known that PDF has in existence much longer than the other formats and users would have enough hands-on experience on the utility of PDF format and what it could actually offer. In contrast to HTML and XBRL, these technologies are relatively new and most of users would have relied on what has been trumpeted by the enthusiastic parties (Locke and Lowe, 2007) without much hands-on experience. Hence, their perceptions on new technologies on the usefulness would be relatively biased when compared to older technologies such as PDF.

In the second part of the results, this study examined whether users' perceptions of usefulness and ease of use influences their preference of reporting format. The results show that the link between users' perceived usefulness and perceived ease of use is consistent with the findings from previous studies reported in the information systems literature (Davis, 1989; Subramaniam, 1994; Adams et al., 1992). Adams et al. (1992) indicate that perceived usefulness is related to preference but that perceived ease of use is less important in determining preference to use a technology. However, this study shows that perceived ease of use is almost as equally important as perceived usefulness when determining preference; a finding which is similar to Davis et al. (1989) and Moore and Benbasat (1991). The findings in this study also show that, in general, participants who were pre-allocated a particular format in the experiment prefer to use the same reporting format in their investment decision tasks.

The findings in this study also support earlier studies in the digital reporting literature that found users have different preferences among the reporting formats (Beattie and Pratt, 2001; 2003; Hodge and Pronk, 2006). Such results show that in general, more participants perceived usefulness in XBRL higher compared to PDF and HTML. However, one perplexing result is that although the participants perceived XBRL as the most useful and easy to use compared to HTML and PDF, irrespective of their preallocated formats, they still preferred other formats if they were asked to perform an investment decision task. For example, the participants in the HTML group perceived 
XBRL as most useful, but they preferred to use HTML (40.9\%) in performing an investment decision task rather than XBRL (36\%). On the other hand, the participants in the XBRL group preferred to use PDF (38\%) over XBRL (26\%). This is consistent with the results shown in Hodge and Pronk (2006) that professional users prefer PDF format over HTML format. One argument that could be derived from this finding could be that participants were not receptive towards XBRL because it is still relatively new, which may have led participants to be reluctant to change, even though they viewed the alternative format as useful.

In the third part of the results, it was revealed that users' perceived usefulness of reporting formats was reflected in their decision accuracy for HTML and XBRL but not PDF. These findings do not parallel the findings reported in the psychology and information systems literature, that perception often disagrees with actual performance (Wright, 1975; Adelbratt and Montgomery, 1980; Davis, 1989; Kleinmuntz and Schkade, 1993). One reason could be because the technologies in previous studies in the literature have been regularly used as compared to the two reporting formats: HTML and XBRL (although may be available, but likely not regularly used). Therefore, perceptions of such formats resulting the same in their decision making task. In contrast to PDF format, the results for this format are consistent to previous studies as such format may have been regularly used.

The results of PDF format show that there was a marginally significant difference between participants' perceived usefulness and their decision accuracy for PDF format. This finding is similar to the findings in previous studies (Wright, 1975; Adelbratt and Montgomery, 1980; Davis, 1989; Kleinmuntz and Schkade, 1993). As it is known, the results of marginally significant difference in perceived usefulness and accuracy in PDF format could also be attributed to users' contentment/ familiarity of this format compared to the other reporting formats. The results, however, is surprising since quite often, after having familiar for a technology for some time, users normally could anticipate the outcome of using that technology.

Another possible reason on the link between perceived usefulness and decision accuracy could be attributed to factors such as work experience (Adams et al., 1992). For example, half of the participants in this study have more than 10 years of accounting experience (refer to table 1). Studies have shown that the more experience decisionmakers have, the higher possibility there is of them predicting their decision outcome correctly because of their wide and in-depth decision-making knowledge (Vera-Munoz et 
al., 2002). This provides some indication that the participants may be able to anticipate their decision outcome with or without reliance on reporting formats even though the results for PDF format show a marginally significant difference between perception and actual performance. In such a situation, their decision outcomes would be similar irrespective of which reporting formats they use ${ }^{16}$.

Participants' perception of ease of use was reflected in the cognitive effort required by participants who were pre-allocated the PDF format. The results indicate that the users who were pre-allocated the PDF format have perceptions similar to their actual performance for ease of use. Such a result could be derived from their familiarity with PDF for investment decision tasks, as most of the participants may be more familiar with the PDF format. As shown in Table 1,38.7\% of the respondents are familiar with PDF formats compared to only $14.5 \%$ and $3.2 \%$ for HTML and XBRL formats.

However, this may not be the case for those participants who were pre-allocated the HTML and XBRL formats. The results show that for participants who were pre-allocated the HTML and XBRL formats, perceived ease of use for the HTML and XBRL formats was not reflected in their actual performance (cognitive effort). The participants perceived that using HTML and XBRL formats would require more cognitive effort than they actually required when performing their tasks. This result is similar to Sproull and Kiesier (1986) who found that users tended to over or under estimate the required effort to complete a task.

The results discussed above are consistent with those reported in the psychology and information systems literature that subjective measures (perceived usefulness and perceived ease of use) of a technology (such as reporting formats) are often in disagreement with their objective counterparts (decision accuracy and cognitive effort) (Wright, 1975; Adelbratt and Montgomery, 1980), possibly caused by lack of knowledge or experience with the reporting formats.

There are some limitations in this study. First, the sample is made up of public accounting practitioners from a certain country, New Zealand. Since it is known that the attitudes towards technological innovations may be influenced by cultural factors, the

\footnotetext{
${ }^{16}$ An ANCOVA test was performed to examine whether the results on decision quality would be different when controlling for experience. The results show that, when controlling for experience, the effect of reporting formats on decision accuracy would be higher when experience is accounted for $(\mathrm{p}=0.062)$ compared when experience is not accounted for $(\mathrm{p}=0.075)$.
} 
results of replication studies in other cultural environments may be different. Further, since this study has only relies on public accounting practitioners, the results may not be generalised to other type of users of financial statements.

Secondly, this study has converted the financial statements to XBRL using Microsoft Excel which were then uploaded to webpage. Of consequence, the participants viewed the information based on one of the reporting formats permitted by the XBRL standard. Although the XBRL format provides hyperlink among certain items in the financial statements, the feature or utility of this format may be different from other available formats such as the Fujitsu or Rivet Software. Hence, the results may be different if other mediating software is used.

Thirdly, the results in this study are based on two groups of participants (in-lab and out-of-lab). Since $62 \%$ of the participants completed the experiment in an out-of-lab setting, this study have to trust the participants in complying to the instructions in completing the research material in one sitting and to rely solely on the information in the research materials when answering questions. Although the results show no significant differences between the time taken and reliability of information usage, the out-of-lab participants cannot eliminate the possibility that uncontrolled factors have affected the results.

Finally, this study relies on Davis (1989) proposition that perceptions of usefulness and ease of use as similar to decision accuracy and cognitive effort. Although effort has been taken to justify the use of decision accuracy and time taken as proxy to decision quality $^{17}$, and the use of these variables to link with perceptions ${ }^{18}$, it could be argued that the perceptions of usefulness and ease of use could not fully represent decision accuracy and cognitive effort.

Overall, the findings of this study provide useful insights on users' perceptions, performances and preferences on the digital reporting formats. Such results provide a holistic and comprehensive view of the importance of perceptions and the effect of reporting format on decision-makers' performance. This is particularly relevant since if more advanced forms of digital reporting are to be encouraged, then there is also the need

\footnotetext{
${ }^{17}$ See Hard and Vanecek (1991); Bricker and Nehmer (1995); Ramarapu et al., (1997); Frownfelter-Lohrke (1998); Dull et al., (2003).

${ }^{18}$ See Davis (1989), Hard and Vanecek (1991).
} 
for users to be made more aware of the benefits to be gained from the different forms of reporting.

\section{REFERENCES}

ADAMS, D.A.; NELSON, R.R.; TODD, P.A. (1992): "Perceived usefulness, ease of use and usage of information technology: A replication", MIS Quarterly, June: 227-247.

ADELBRATT, T.; MONTGOMERY, H. (1980): “Attractiveness of decision rules", Acta Psychologica, vol. 45: 177-185.

ALLAM, A.; LYMER, A. (2003): "Development in Internet Financial Reporting: Review and Analysis across Five Developed Countries", International Journal of Digital Accounting Research, vol. 3(6).

ALMER, E.D.; HOPPER, J.R.; KAPLAN, S.E. (2003): "A research tool to increase attention to experimental materials: Manipulating presentation format", Journal of Business and Psychology, vol. 17 (3): 405-417.

ANDERSON, J.C.; KAPLAN, S.E. (1992): "An investigation of the effect of reporting format on auditors' non investigation region judgments', Advances in Accounting Information Systems, vol. 1: 71-88.

ARTHUR ANDERSEN, A. (2000): Spice up the Story: A Survey of Narrative Reporting in Annual Reports, Arthur Andersen, London.

ASHBAUGH, H.; JOHNSTONE, K.M.; WARFIELD, T.D (1999): "Corporate reporting on the internet", Accounting Horizons, vol. 13(3): 241-257.

ASHTON, A.H. (1991): "Experience and error frequency knowledge as potential determinants of audit professionalism", The Accounting Review, April: 218-239.

BALDWIN, A.A.; BROWN, C.E.; TRINKLE, B.S. (2006): "XBRL: The Future of Financial Reporting: A Research Challenge", Journal of Emerging Technologies in Accounting, vol. 3: 97-116.

BEACH, L.R.; MITCHELL, T.R. (1978): "A contingency model for the selection of decision strategies", Academy of Management Review, vol. 3: 439-449.

BEATTIE, V.; PRATT, K. (2001): Business Reporting: Harnessing the Power of the Internet for Users, Institute of Chartered Accountants of Scotland, Edinburgh. 
BEATTIE, V.; PRATT, K. (2003): "Issues concerning web-based business reporting: an analysis of the views of interested parties", The British Accounting Review, vol. 35(2):155-187.

BERTIN, J. (1983): The semiology of graphics, University Wisconsin Press, Madison, Wisconsin.

BIZARRO, P.A.; BALDWIN, A.A. (2004): "The importance of cognitive style in information retrieval tasks", Submitted to the International Journal of Accounting of Information Systems.

BRICKER, R.; NEHMER, R. (1995): "Information presentation format, degree of information processing and decision quality", Advances in Accounting Information Systems, vol. 3: 3-29.

BUTLER, J.B.; MAUTZ , R.D. (1996): "Multimedia presentations and learning: A laboratory experiment", Issues in Accounting Education, vol. 11(2): 259-281.

CLEMENTS, C.E.; WOLFE, C. (1998): “An experimental analysis of multimedia annual reports on non-professional users", Advances in Accounting Information Systems, vol. 5: 105-136.

CLEMENTS, C.E.; WOLFE, C. (2000): "Reporting financial results with the video medium: an experimental analysis", Journal of Information Systems, Vol.14: 79-94.

CRAVEN, B.M.; MARSTON, C.L. (1999): "Financial reporting on the internet by leading UK companies", European Accounting Review, vol. 8(2): 321-333.

DAVIS, F.D. (1989): "Perceived usefulness, perceived ease of use and user acceptance of information technology”, MIS Quarterly, September: 319-340.

DELLER, D.; STUBENRATH, M.; WEBER, C. (1999): "A Survey on the use of the Internet for Investor Relations in the USA, UK and Germany", European Accounting Review, vol. 8(2): 289-301.

DICKSON, G.W.; DE SANCTIS, G.; MC BRIDE, D.J. (1986): "Understanding the effectiveness of computer graphics for decision support: A cumulative experimental approach", Communications of the ACM, vol. 29(1): 40-47.

DULL, R.B.; GRAHAM, A.W.; BALDWIN, A.A. (2003): "Web-based Financial Statements: Hyperlinks to Footnotes and their Effect on Decisions", International Journal of Accounting Information Systems, vol. 4: 185-203. 
DUNN, C.L.; GRABSKI, S.V. (2000): "Perceived semantic expressiveness of accounting systems and task accuracy effects", International Journal of Accounting Information Systems, vol.1 (2): 79-87.

FROWNFELTER-LOHRKE, C. (1998): "The effects of differing reportings of general purpose financial statements on users' decisions", Journal of Information Systems, vol. 12(2): 99-107.

FISHER, R.; OYELERE, P.; LASWAD, F. (2004): "Corporate Reporting on the Internet: Audit Issues and Content Analysis of Practices", Managerial Auditing Journal, vol. 19(3): 412-439.

GOLDWATER, P.M.; FOGARTHY, T.J. (1995): "Cash flow decision making and financial accounting reporting: A computerized experiment", Journal of Applied Business Research, vol. 11(3): 16-29.

HARD, N.J.; VANECEK, M.T. (1991): "The implications of tasks and format on the use of financial information”, Journal of Information Systems, Fall: 35-49.

HODGE, F. (2001): "Hyperlinking un-audited information to audited financial statements: Effects on investor judgments", The Accounting Review, vol. 76(10): 675691.

HODGE, F.; KENNEDY, J.J.; MAINES, L.A. (2002): "Recognition versus disclosure in financial statements: Does search-facilitating technology improve transparency?", Unpublished working paper: http://www.hamscher.com/xbrl/ Hodge-Kennedy-MainesXBRL-2002-11.pdf.

HODGE, F.D.; KENNEDY, J.J.; MAINES, L.A. (2004), "Does search facilitating technology improve the transparency of financial reporting?", Accounting Review, vol. 79 (3): 687-703.

HODGE, F.; PRONK, M. (2006): "The impact of expertise and investment familiarity on investors' use of online financial reporting information", Journal of Accounting, Auditing and Finance, Summer: 267-292.

ISELIN, E. R. (1988): "The effects of information load and information diversity on decision quality in a structured decision task", Accounting, Organizations and Society, vol.13(2): 147-164. 
KIDA, T.; SMITH, J.F.; MALETTA, M. (1998): "The effects of encoded memory traces for numerical data on accounting decision-making", Accounting, Organisations and Society, vol. 23(5): 585-610.

KLEINMUNTZ, D.N.; SCHKADE, D.A. (1993): "Information Displays and Decision Processes", American Psychology Society, vol. 4(4): 221-227.

LASWAD, F.; FISHER, R.; OYELERE, P. (2005): "Determinants of voluntary internal financial reporting by local government authorities", Journal of Accounting and Public Policy, vol. 24: 101-121.

LIBBY, R.; LEWIS, B.L. (1977): "Human information processing research in accounting: The state of the Art", Accounting, Organizations and Society, vol. 2(3): 245268.

LIBBY, R.; LEWIS, B.L. (1982): "Human information processing research in accounting: The start of the art in 1982", Accounting, Organizations and Society, vol. 7(3): 231-285.

LOCKE, J.; LOWE, A. (2007): "XBRL: An (Open) Source of Enlightenment or Disillusion?", European Accounting Review, vol. 16(3): 585-623.

LYMER, A. (1999): "The internet and the future of corporate reporting in Europe", European Accounting Review, vol. 8(2): 289-301.

LYMER, A.; TALLBERG, A. (1997): "Corporate Reporting and the Internet - A Survey and Commentary on the use of the WWW in Corporate Reporting in the UK and Finland", Paper Presented at EAA'97, Graz, Austria.

MACKAY, D.B.; VILLAREAL, A. (1987): "Performance differences in the use of graphic and tabular displays of multivariate data", Decision Sciences, vol. 18: 535-546.

MACKAY, J.M.; BARR, S.H.; KLETKE, M.G. (1992): “An empirical investigation on the effects of decision aids on problem solving processes", Decision Sciences, vol. 23: 648-672.

MAINES, L.A. (1995): "Judgment and decision making research in financial accounting: a review and analysis", in Judgment and Decision Making Research in Accounting and Auditing, Cambridge University Press: 77-131. 
MOORE, G,C.; BENBASSAT, I. (1991): "The development of an instrument to measure he perceived characteristics of adopting an information technology innovation", Information Systems Research, vol. 1(3): 192-222.

OYELERE, P.; LASWAD, F.; FISHER, R. (2003): "Determinants of internet financial reporting by New Zealand companies", Journal of International Financial Management and Accounting, vol. 14(1): 26-59.

PANKO, R. (1983): “Options in electronic mail”, Office Administration and Automation, vol. 44(11): 50-96.

PAZNIK, M. (1987): "Voice mail: Pitfalls and Promises", Administrative Management, vol. 48(3): 16-25.

PURVIS, S. E. (1989): "The effect of audit documentation format on data collection", Accounting, Organisations and Society, vol. 14(5-6): 551-563.

RAMARAPU, N.K.; FROLICK, M.N.; WILKES, R.B.; WETHERBE, J.C. (1997): “The emergence of hypertext and problem solving: An experimental investigation of assessing and using information from linear versus nonlinear systems", Decision Sciences, vol. 28(4): 825-849.

RICE, R.E.; STEINFIELD, C. (1991): "Experiences with new forms of organizational communication via electronic mail and voice messaging", in Telematics and Work, J.H Anderson and R. Roe (eds), Wiley, New York.

ROHRMANN, B. (1986): "Evaluating the usefulness of decision aids: A methodological perspective", in New Directions in Research on Decision Making, B. Brehmen, H. Jungermann, P Lourens, \& G. Sevon (Eds.), Amsterdam: North-Holland.: 363-381.

ROSE, J.M. (2002), "The effects of multimedia-induced affective states on recall and decision making by individual investors", International Journal of Accounting Information Systems, vol. 2: 22-40.

SEC (2005): SEC Announces Initiative to Assess Benefits of Tagged Data in Commission Filings. Securities and Exchange Commission, http://www.sec.gov/ raws/press.2005.

SEC (2007): SEC Chairman Cox Announces Landmark Progress in Providing Instant, User-Friendly Access to Financial Reporting Information for Investors, Securities and Exchange Commission, http://www.sec.gov/news/press/2007/2007-200.htm 
SMITH, B. (2003): "Financial Reporting on the Internet: A Question of Integrity", Paper presented at the 4th International Conference for the British Accounting Association Special Interest Group in Corporate Governance.

SPROULL, L.; KIESIER, S. (1986): "Reducing social context cues: Electronic mail in organizational communication”, Management Science, vol. 32(4): 1492-1512.

STOCK, D.; WATSON, C.J. (1984): "Human judgment accuracy, multidimensional graphics and human versus models", Journal of Accounting Research, Spring: 192-206.

STRAUB, D.W.; WETHERBE, J.C. (1989): “Information technologies for the 1990's: An organizational impact perspective", Communications of the ACM, vol. 32(11): 13281339.

STONE, D.N.; SCHKADE, D.A. (1991): "Numeric and linguistic information reporting in multi-attribute choice", Organizational Behavior and Human Decision Processes, vol. 49: 42-59.

SUBRAMANIAM, G.H. (1994): "A replication of perceived usefulness and perceived ease of use measurement", Decision Sciences, vol. 25(5/6): 863-874.

TAYLOR, D.; BROWNFIELD, N. (2002): "Perceived usefulness and ease of use of websites: Evidence of the impact of Website design features", Malaysian Accounting Review, September: 23-37.

TUTTLE, B.; KERSHAW, R. (1998): "Information presentation and judgment strategy from a cognitive fit perspective", Journal of Information Systems, vol. 12(1): 1-17.

VERA-MUÑOZ, S.C.; KINNEY, W.R.; BONNER, S.E. (2001): "The effects of domain experience and task reporting format on accountants' information relevance assurance", The Accounting Review, vol. 76(3): 405-429.

VESSEY, L.(1991): "Cognitive fit: A theory-based analysis of the graphs versus tables literature”, Decision Sciences, Spring: 219-240.

XBRL New Zealand (2004), http://www.xbrl.org/nmpxbrl.aspx?id=98.

WATSON, C.J.; DRIVER, R.W. (1983): "The influence of computer graphics on the recall of information", MIS Quarterly, vol. 7(1): 45-53.

WRIGHT, P.L. (1975): "Consumer choice strategies: Simplifing versus optimizing", Journal of Marketing Research, vol.11: 60-67. 
WU, J.; VASARHELYI, M. (2004): "XBRL: A New Tool for Electronic Financial Reporting", in Business Intelligence Techniques: A Perspective from Accounting and Finance, Springer: 73-92. 


\section{APPENDIX A: PART OF REPORTING FORMATS USED IN THE STUDY}

\section{PDF Document}

\begin{tabular}{|c|c|c|}
\hline \multicolumn{3}{|c|}{$\begin{array}{c}\text { FIRM A } \\
\text { STATEMENT OF FINANCIAL PERFORMANCE }\end{array}$} \\
\hline Year ended 31 December & $\begin{array}{c}2005 \\
\$\end{array}$ & $\begin{array}{c}2004 \\
\$\end{array}$ \\
\hline Sales & $1,695,771$ & 933,754 \\
\hline Cost of sales & $\underline{1.460,797}$ & 713,740 \\
\hline Gross Profit & 234,974 & 270,014 \\
\hline General and administrative expense & 77,631 & 90,719 \\
\hline Salary expense & 28,577 & 30,092 \\
\hline Research and development expense & 30,000 & 40,000 \\
\hline Interest and other finsncing expense, net & $\underline{25,948}$ & $\underline{24.122}$ \\
\hline Operating income & 72,818 & 85.081 \\
\hline Other income & $\underline{61.603}$ &. .500 \\
\hline Net income before $\operatorname{tax}$ & 134,421 & 89,581 \\
\hline Income tax expense & $\underline{20,000}$ & $\underline{8, S B S}$ \\
\hline Net income (Loss) & 114,421 & 80,693 \\
\hline Zarnings (loss) per share - basic & 0.20 & 0.14 \\
\hline
\end{tabular}

See Accompanying Notes to Financial Statements

FIRMA

STATEMENT OF FINANCIAL POSITION

\begin{tabular}{|c|c|c|}
\hline Year ended 31 December & $\begin{array}{c}2005 \\
\$\end{array}$ & $\begin{array}{c}2004 \\
5\end{array}$ \\
\hline \multicolumn{3}{|l|}{ Fixed Assets: } \\
\hline Property, plont and equipment (net) & 535,263 & 410,082 \\
\hline Other assets & 272,888 & 217,888 \\
\hline \multirow[t]{2}{*}{ Investment } & 124.000 & 107.972 \\
\hline & 932,151 & 735,942 \\
\hline \multicolumn{3}{|l|}{ Current Assets: } \\
\hline Inventories & 239,458 & 208,260 \\
\hline Accounts receivables & 149,606 & 114,772 \\
\hline Cash & 20,646 & 11,707 \\
\hline \multicolumn{3}{|l|}{ Less: Current Liabalities } \\
\hline Accounts payable & 298,579 & 239,879 \\
\hline Notes payable & 152,985 & 140,854 \\
\hline Other current liabilities & 43.340 & 11.440 \\
\hline Total Net Assets & 846,957 & 678,508 \\
\hline \multicolumn{3}{|l|}{ Shareholders' Equity } \\
\hline Common stocl: & 567,815 & 567,815 \\
\hline Retained Esrnings (Loss) & 131,142 & 19,307 \\
\hline \multicolumn{3}{|l|}{ Long Term Linbilities } \\
\hline Long term debt & 148.000 & 130.000 \\
\hline $\begin{array}{l}\text { Totnl Shareholders' Equity and Long Term } \\
\text { Liabilities }\end{array}$ & 846,957 & 678,508 \\
\hline
\end{tabular}

See Accompanying Notes to Financial Statements 


\section{HTML document}

Please select one of the firms below to begin your analysis

FIRM A

- Statement of Financial Performance

- Statement of Financial Position

- Cash Flow Statement

- Notes

\section{- HTML document downloaded using Microsoft word}

FIRM A

Statement of Financial Performance

\begin{tabular}{|l|l|l|}
\hline Year ended 31 December & \multicolumn{1}{|c|}{$\mathbf{2 0 0 5} \mathbf{( \$ )}$} & \multicolumn{1}{c|}{$\mathbf{2 0 0 4}(\mathbf{\$ )}$} \\
\hline Sales & $1,695,771$ & 983,754 \\
\hline Cost of sales & $\underline{1,460,797}$ & $\underline{713,740}$ \\
\hline Gross Profit & 234,974 & 270,014 \\
\hline & & \\
\hline General and administrative expense & 77,631 & 90,719 \\
\hline Salary expense & 28,577 & 30,092 \\
\hline Research and development expense & 30,000 & 40,000 \\
\hline Interest and other financing expense, net & $\underline{25,948}$ & $\underline{\mathbf{2 4 , 1 2 2}}$ \\
\hline & & \\
\hline Operating income & 72,818 & 85,081 \\
\hline Other income & $\underline{61,603}$ & $\underline{4,500}$ \\
\hline Net income before tax & 134,421 & 89,581 \\
\hline & & \\
\hline Income tax expense & $\underline{20,000}$ & $\underline{8,888}$ \\
\hline & & $\mathbf{8 0 , 6 9 3}$ \\
\hline Net income (Loss) & $\mathbf{1 1 4 , 4 2 1}$ & \\
\hline & & $\mathbf{0 . 1 4}$ \\
\hline Earnings (loss) per share - basic & $\mathbf{0 . 2 0}$ & \\
\hline & & \\
\hline
\end{tabular}


- XBRL

XBRL

Experimental

Exercise

Firm-A
This application will allow you to perform a quick analysis of XBRL/XML data for the purpose of Experimental Exercise. The download will be transferred via XBRL/XML, where pivot table analysis and ratios will be created via Microsoft Office VBA.

\section{Should use for the purpose of Experimental Exercise only}

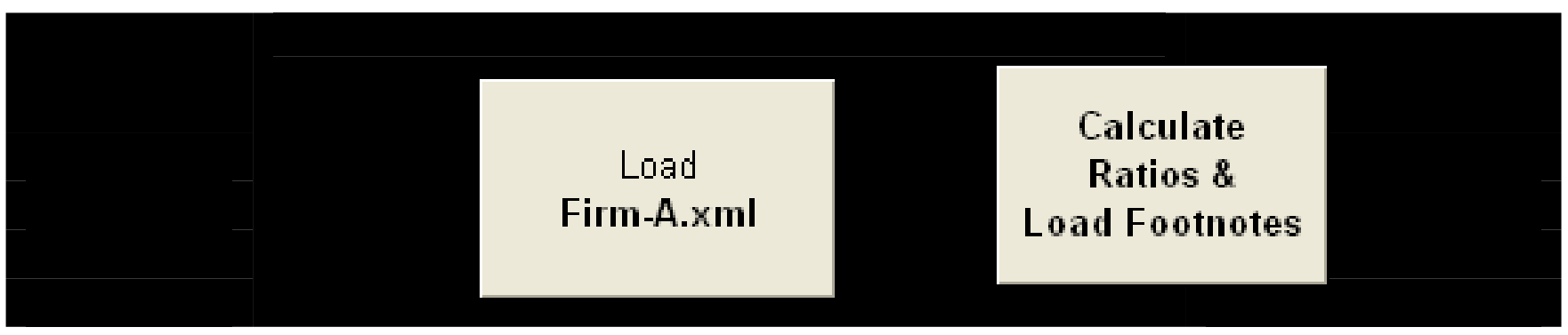

\section{XBRL document downloaded using Excel}

\begin{tabular}{|l|r|r|r|}
\hline Elements Financial Table & & & \\
\hline Sum of value & \multicolumn{1}{|l|}{ Year } & & \multicolumn{1}{|c|}{} \\
\hline Newelement & \multicolumn{2}{|l|}{2004} & \multicolumn{2}{|c|}{ Grand Total } \\
\hline Account Receivables & 114772 & 149606 & 264378 \\
\hline Cash & 11707 & 20646 & 32353 \\
\hline Inventories & 208260 & 239458 & 447718 \\
\hline Investment & 107972 & 124000 & 231972 \\
\hline Net Income / Loss & 80693 & 114421 & 195114 \\
\hline Net Income Before Tax & 89581 & 134421 & 224002 \\
\hline Other Assets & 217888 & 272888 & 490776 \\
\hline Property, Plant and Equipment & 410082 & 535263 & 945345 \\
\hline Sales & 983754 & 1695771 & 2679525 \\
\hline Total Net Assets & 678508 & 846957 & 1525465 \\
\hline
\end{tabular}




\begin{tabular}{|c|c|c|c|}
\hline \multicolumn{4}{|c|}{ Financial Item Notes (Footnotes) } \\
\hline Newelement & Year & Value & Footnote \\
\hline $\begin{array}{l}\text { Account } \\
\text { Receivables }\end{array}$ & 2005 & 149606 & $\begin{array}{l}\text { Accounts receivable are stated at net of an allowance for doubtful } \\
\text { accounts equal to approximately } 1 \% \text { of sales. }\end{array}$ \\
\hline Other Assets & 2005 & 272888 & $\begin{array}{l}\text { Other assets are stated at cost and amortized using the straight line } \\
\text { method over the estimated useful lives, which range from five to } \\
\text { eight years. The firm evaluates the possible impairment of long lived } \\
\text { assets, including intangible assets, whenever events or circumstances } \\
\text { indicate the carrying value of the assets may not be recoverable. The } \\
\text { firm currently has no goodwill. }\end{array}$ \\
\hline $\begin{array}{l}\text { Other Current } \\
\text { Liabilities }\end{array}$ & 2005 & 43340 & $\begin{array}{l}\text { Other current liabilities consist of warranty costs, professional fees } \\
\text { and miscellaneous acquisition costs. }\end{array}$ \\
\hline Other Income & 2005 & 61603 & $\begin{array}{l}\text { The firm's investments consist of investment properties, specifically } \\
\text { land. In accordance with IAS } 40 \text {, investments properties can be } \\
\text { accounted for using the fair value method or the cost method. Under } \\
\text { the cost method, the firm did not recognized unrealized gain on the } \\
\text { statement of financial performance. Just merely disclose the fair } \\
\text { value of the investment properties in the notes. An alternative } \\
\text { method of accounting for investment properties is the fair value } \\
\text { method in which any unrealized gain will be recognized in the } \\
\text { statement of financial performance. The firm adopted the fair value } \\
\text { method, and recognized the increase value of the investment } \\
\text { properties on the statement of financial performance. The market } \\
\text { value of the investments is currently at } \$ 124,000 \text {. Had the firm } \\
\text { adopts the cost model, the firm's other income for } 2005 \text { would have } \\
\text { been } \$ 45,575 \text { and the net income before tax would have been } \\
\$ 118,393 \text {. }\end{array}$ \\
\hline Investment & 2005 & 124000 & $\begin{array}{l}\text { The firm's investments consist of investment properties, specifically } \\
\text { land. In accordance with IAS 40, investments properties can be } \\
\text { accounted for using the fair value method or the cost method. Under } \\
\text { the cost method, the firm did not recognized unrealized gain on the } \\
\text { statement of financial performance. Just merely disclose the fair } \\
\text { value of the investment properties in the notes. An alternative } \\
\text { method of accounting for investment properties is the fair value } \\
\text { method in which any unrealized gain will be recognized in the } \\
\text { statement of financial performance. The firm adopted the fair value } \\
\text { method, and recognized the increase value of the investment } \\
\text { properties on the statement of financial performance. The market } \\
\text { value of the investments is currently at } \$ 124,000 \text {. Had the firm } \\
\text { adopts the cost model, the firm's other income for } 2005 \text { would have } \\
\text { been } \$ 45,575 \text { and the net income before tax would have been } \\
\$ 118,393 \text {. }\end{array}$ \\
\hline
\end{tabular}




\section{APPENDIX B: RESEARCH MATERIAL}

\begin{tabular}{|c|c|}
\hline $\begin{array}{l}\text { INSTRUCTIONS } \\
\text { Each participant would receive two envelopes. It is } \\
\text { important that the correct sequence is followed } \\
\text { when opening the envelopes and completing the } \\
\text { requirements set out therein. You should start with } \\
\text { Envelope } 1 \text { and complete the experiment exercise } \\
\text { before opening Envelope } 2 \text {. It is important that the } \\
\text { requirements of Envelope } 2 \text { be completed }\end{array}$ & $\begin{array}{l}\text { EXPERIMENTAL EXERCISE } \\
\text { Enclosed is a CD containing the experiment exercise. } \\
\text { On opening the CD, click on the index file and in that } \\
\text { file, you will see general instructions similar to the } \\
\text { one below. Please select the group allocated to you } \\
\text { (Group one or Group two) as stated on the envelope } \\
\text { and proceed to begin the experiment exercise. }\end{array}$ \\
\hline $\begin{array}{l}\text { set out in Envelope } 1 . \\
\text { Upon the completion of the requirements set out in } \\
\text { Envelope } 1 \text { and } 2 \text {, it would be greatly appreciated if } \\
\text { these can be returned in the provided self addressed } \\
\text { envelope at your earliest convenience. } \\
\text { Envelope } 1 \text { : Experimental Exercise } \\
\text { Envelope } 2 \text { : Post experimental questionnaire } \\
\text { To begin the experiment exercise, please open } \\
\text { Envelope } 1 .\end{array}$ & $\begin{array}{l}\text { GENERAL INSTRUCTIONS } \\
\text { Experiment Exercise } \\
\text { You are to assume the role of an investor with } \\
\$ 10,000 \text { to invest in the equity capital of one, or both } \\
\text { of the following firms: Firm A and Firm B. The } \\
\text { following factors are critical to the financial } \\
\text { performance and earnings potential of these firms: } \\
\text { - Return on assets (net income before tax/ total } \\
\text { assets) } \\
\text { - Return on sales (net income before tax/ total sales) } \\
\text { - Return on fixed assets (net income before tax/ } \\
\text { fixed assets) } \\
\text { - Fixed asset turnover (sales/ fixed asset) } \\
\text { Your task is to evaluate the financial performance and } \\
\text { earnings potential of Firm A and Firm B. At the } \\
\text { conclusion of your analysis, please indicate how you } \\
\text { would invest your } \$ 10,000 \text { by comparing Firm A and } \\
\text { Firm B. } \\
\text { The information provided in the CD is not intended to } \\
\text { be fully representative of what would be available to } \\
\text { you if you were to undertake a detailed evaluation of } \\
\text { Firm A and Firm B. Nevertheless, while completing } \\
\text { the case, please base your judgments only on the } \\
\text { information provided. Please do not consult with } \\
\text { others or use additional material. } \\
\text { Please preview the Financial Statements of Firm A } \\
\text { and Firm B } \\
\text { PREVIEW } \\
========\end{array}$ \\
\hline
\end{tabular}




\section{EXPERIMENTAL EXERCISE}

- You may view the information contained on the $C D$ when answering this questionnaire.

- After you have answered a question, please do not go back and change your response.

Q.1 Please record the starting time:

$\mathrm{Hr} / \mathrm{Mi}$

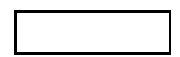

Q.2 Please fill in the numerator and denominator for the following four ratios for Firm A.

The ratios to be calculated are for the $\mathbf{2 0 0 5}$ year.

Return on assets (net income before tax/ total assets)

Return on sales (net income before tax/ total sales)

Return on fixed assets (net income before tax/ fixed assets)

Fixed asset turnover (sales/ fixed asset)

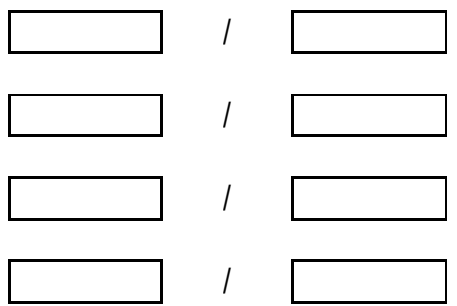

Q.3 Please fill in the numerator and denominator for the following four ratios for Firm B.

The ratios to be calculated are for the $\mathbf{2 0 0 5}$ year.

- Return on assets (net income before tax/ total assets)

- Return on sales (net income before tax/ total sales)

- $\quad$ Return on fixed assets (net income before tax/ fixed assets)

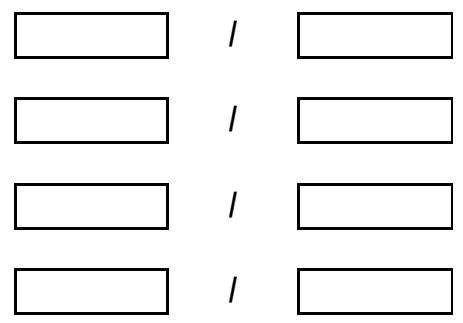

- $\quad$ Fixed asset turnover (sales/ fixed asset)

\section{Q.4 Please record the time}

$\mathrm{Hr} / \mathrm{Min}$

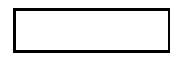

Q.5 I believe that overall, Firm A's financial performance for the 2005 year outperforms Firm B's financial performance. Please indicate using the following scale.

$\begin{array}{llllllllll}\text { Strongly Disagree } & 1 & 2 & 3 & 4 & 5 & 6 & 7 & \text { Strongly Agree }\end{array}$

Q.6 If you had to invest $\$ 10,000$ in one firm, which firm would you invest in? (Please tick)

Firm A

Firm B 
Q.7 If you could invest in both firms, what percentage would you invest in each (the total must add up to 100)

Firm A

Firm B

Total

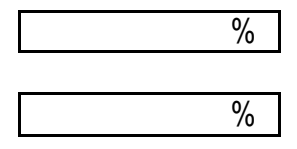

$100 \%$

Q.8 Please record the completion time

$\mathrm{Hr} / \mathrm{Min}$

You have completed stage one of the research project. Please proceed immediately to Envelope 2. Thank you.

\section{POST EXPERIMENTAL QUESTIONNAIRE}

SECTION A

Important note: Please load the $\mathrm{CD}$ enclosed in Envelope 2. On opening the $\mathrm{CD}$, click on the index file and in that file, you will see general instructions similar to the one in experiment one. Please browse and review through the three formats on the $\mathrm{CD}$ (these digital reporting format being PDF, HTML and XBRL) before you proceed to this section. Please indicate your opinion on the perceived usefulness of each of the three digital reporting format..

Please do not dwell on the selection of score rather go with your initial 'gut' feeling.

\section{SCALE \\ $\begin{array}{lllllllll}\text { Strongly Disagree } & 1 & 2 & 3 & 4 & 5 & 6 & 7 & \text { Strongly Agree }\end{array}$}

Q1. The reporting format would enable me to accomplish my investment decision task more quickly.
a. PDF
2
3
4
5
6
7
b. HTML
23
34
5
6
7
c. XBRL
2
3
4
5
6
7

Q2. The reporting format would enable me to make a more informed investment decision.
a. PDF
23
4
6
7
b. HTML
23
4
5
6
7
c. XBRL
1
23
4
5
6
7

Q3. The reporting format is very useful for identifying information (well-formatted)
a. PDF
23
4
5
6
7
b. HTML
2
3
4
5
6
7
c. XBRL
1
23
4
5
6
7 
Q.4 The reporting format allows me to gather more information for the investment decision task.
a. PDF
23
4
$5 \quad 6$
7
b. HTML
23
4
5
6
7
c. XBRL
23
4
5
7

Q5. The reporting format contains too much irrelevant information for investment decision task.
a. PDF
23
4
$5 \quad 6$
7
b. HTML
23
4
5
6
7
c. XBRL
23
4
5
6
7

Q6. The reporting format provides me with sufficient information for investment decision task.
a. PDF
23
4
5
6
7
b. HTML
23
4
5
6
7
c. XBRL
23
4
5
6
7

Q7. I do not have to rely on other reporting format upon relying on this reporting format to perform my investment decision task.
a. PDF
23
4
5
6
7
b. HTML
23
4
5
$6 \quad 7$
c. XBRL
23
4
5
$\begin{array}{ll}6 & 7\end{array}$

Q8. I would find the reporting format useful in performing the investment decision task.
a. PDF
23
4
5
6
7
b. HTML
2
3
4
5
$\begin{array}{ll}6 & 7\end{array}$
c. XBRL
23
4
5
6
7

Q9. Overall, I find the reporting format is useful for the investment decision task.
a. PDF
23
4
5
$6 \quad 7$
b. HTML
23
4
5
$6 \quad 7$
c. XBRL
23
4
5
6
7

\section{SECTION B}

Please indicate your opinion on the perceived ease of use of each digital reporting format. Please do not dwell on the selection of score rather go with your initial 'gut' feeling.

\section{SCALE}

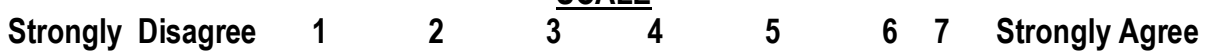


Q1. I can easily learn how to use the reporting format

\begin{tabular}{|c|c|c|c|c|c|c|}
\hline a. PDF & 1 & 2 & 3 & 4 & 5 & 6 \\
\hline b. HTML & 1 & 2 & 3 & 4 & 5 & 6 \\
\hline c. XBRL & 1 & 2 & 3 & 4 & 5 & 6 \\
\hline
\end{tabular}

Q2. The reporting format is very clear and understandable.

\begin{tabular}{|c|c|c|c|c|c|c|c|}
\hline a. & PDF & 1 & 2 & 3 & 4 & 5 & 6 \\
\hline b. & HTML & 1 & 2 & 3 & 4 & 5 & 6 \\
\hline c. & XBRL & 1 & 2 & 3 & 4 & 5 & 6 \\
\hline
\end{tabular}

Q3. I can easily become skilful in using the reporting format.

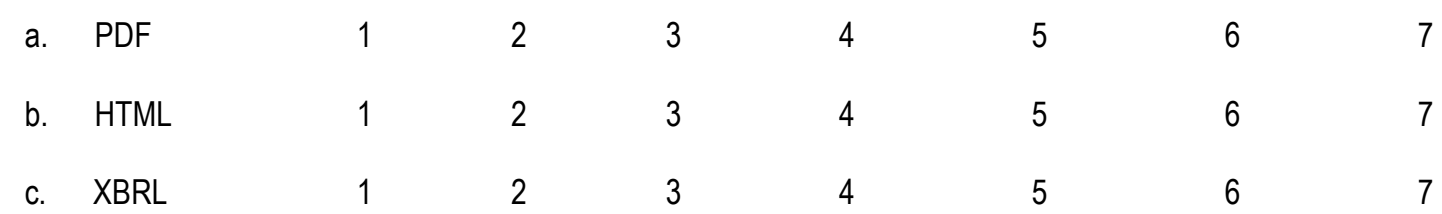

Q4. I can easily find the information that I require for my investment decision task.
a. PDF
23
45
$6 \quad 7$
b. HTML
23
4
5
$6 \quad 7$
c. XBRL
23
4
5
$6 \quad 7$

Q5. The reporting format enables to easily retrieve and manipulate the information for the investment decision task.
a. PDF
23
4
$6 \quad 7$
b. HTML
23
4
5
$6 \quad 7$
c. XBRL
23
4
5

$6 \quad 7$

Q6. Further training will improve my performance in using the reporting format.
a. PDF
23
4
5
$6 \quad 7$
b. HTML
23
4
5
6
7
c. $\mathrm{XBRL}$
23
4
5

$6 \quad 7$

Q7. Overall, I find the reporting format is very easy to use.
a. PDF
23
4
5
b. HTML
23
4
5
6
7
c. $\mathrm{XBRL}$
23
4
5
6
7 


\section{SECTION C}

\section{Demographic profile}

Q1. Gender

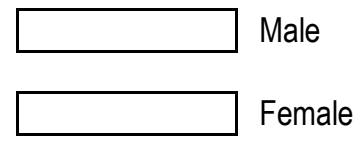

Q2. Age

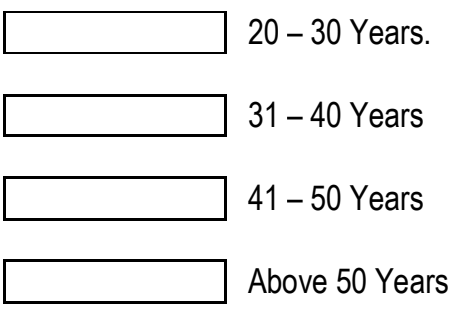

Q3. Educational Background

Bachelors Degree

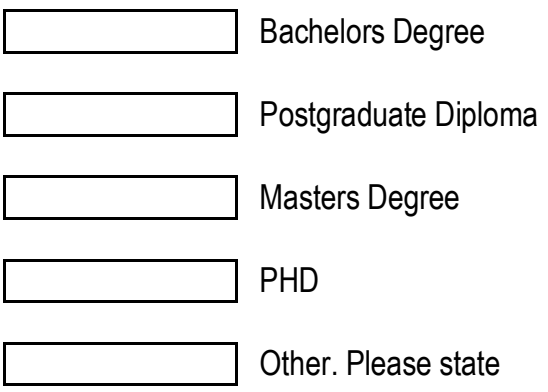

Q4. Are you a member of professional body?

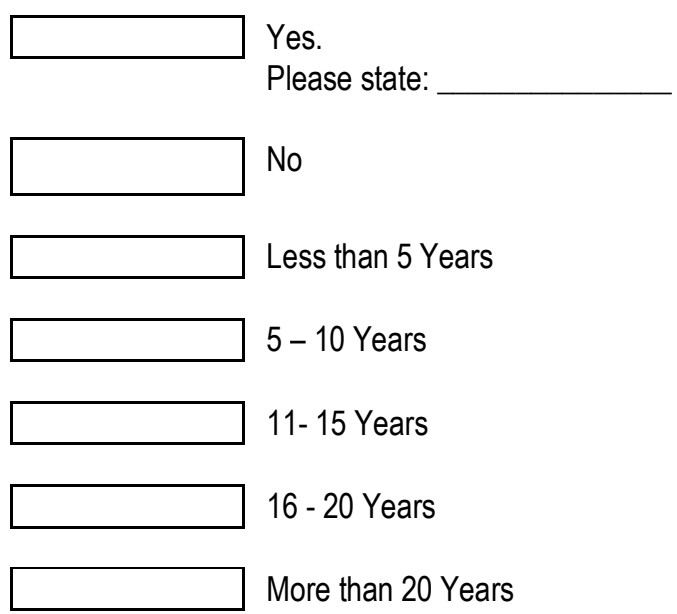

Q5. Total work experience

More than 20 Years

Q6. How familiar are you with relying on the following reporting format in making investment decisions?

\section{Not familiar}
a. PDF
b. HTML
c. XBRL

12

1

1

1
2

23

2
3

4

$5 \quad 6$

$7 \quad$ Familiar

3

45

5

5

67

4

6

7

4

5

6 
Q7. If you had the choice between using PDF, HTML and XBRL in completing the experiment, which would you prefer? Please tick one only
a. PDF
b. HTML
c. XBRL

Please state the reason(s) to your answer

You have completed the post experimental questionnaire. Please return the experiment exercise and post experimental questionnaire in the self addressed envelope. Thank you. 